\title{
Supporting Information for: Molecularly Tunable Polyanions for Single-Ion Conductors and Poly(Solvate Ionic Liquids)
}

\author{
Wenxu Zhang, ${ }^{\dagger}$ Shuting Feng, ${ }^{\ddagger}$ Mingjun Huang, ${ }^{\dagger}$ Bo Qiao, ${ }^{\dagger}$ Keisuke Shigenobu, ${ }^{\S}$ Livia \\ Giordano,\|, Jeffrey Lopez,\| Ryoichi Tatara,\| Kazuhide Ueno, ${ }^{\S}$ Kaoru Dokko, ${ }^{\S}$ Masayoshi \\ Watanabe, "Yang Shao-Horn, ${ }^{*} \|$, and Jeremiah A. Johnson ${ }^{*}, \dagger$ \\ 'Department of Chemistry, Massachusetts Institute of Technology, Cambridge, Massachusetts 02139, United States. \\ *Department of Chemical Engineering, Massachusetts Institute of Technology, Cambridge, Massachusetts 02139, \\ United States. \\ $\S$ Department of Chemistry and Life Science, Yokohama National University, 79-5 Tokiwadai, Hodogaya-ku, \\ Yokohama 240-8501, Japan \\ \|Research Laboratory of Electronics, Massachusetts Institute of Technology, Cambridge, Massachusetts 02139, \\ United States. \\ Department of Mechanical Engineering, Massachusetts Institute of Technology, Cambridge, Massachusetts 02139, \\ United States. \\ IInstitute of Advanced Sciences, Yokohama National University, 79-5 Tokiwadai, Hodogaya-ku, Yokohama 240- \\ 8501, Japan
}




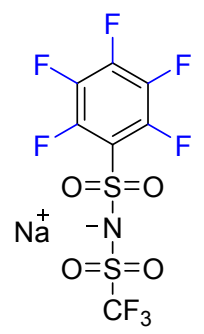

A

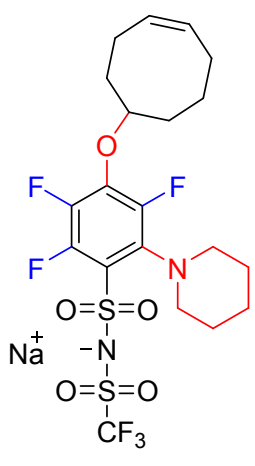

A-ON

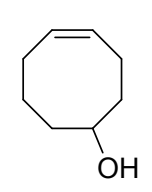<smiles>CC(=O)SC1CCC=CCCC1</smiles>

COE-ol COE-S-ester

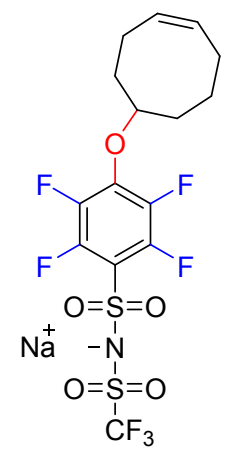

A-O

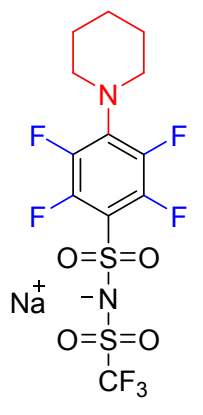

A-N

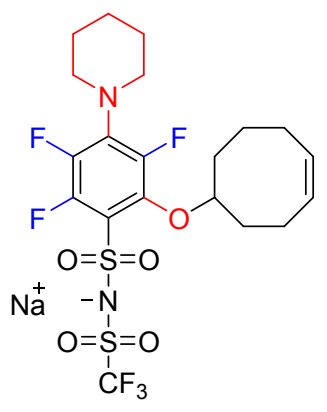

A-NO

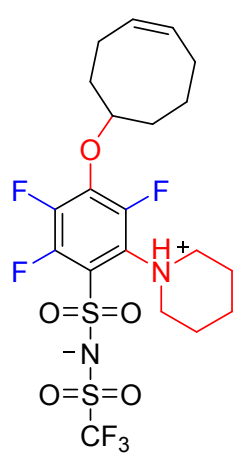

A-ON ${ }^{+}$

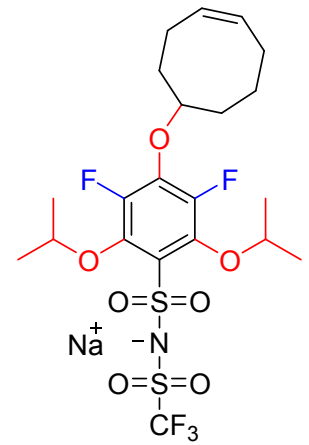

A-00O

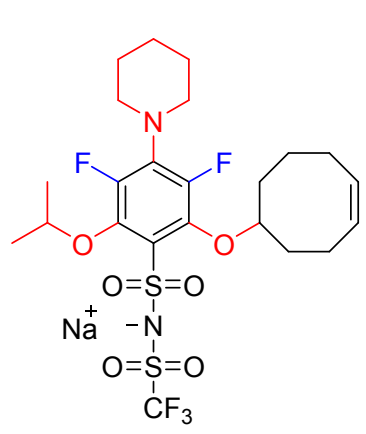

A-NOO

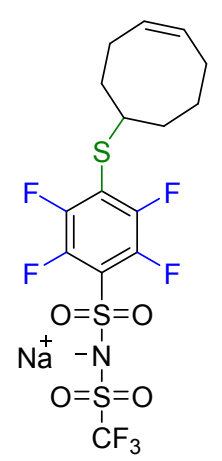

A-S

Scheme S1. Chemical structures of salts, precursors, and FAST-cyclooctene salt monomers used in this work. 


\section{S1. Materials and Methods.}

\section{Materials}

Reagents and solvents were used as received from Sigma Aldrich or Alfa Aesar without further purification. 2,2'-Azobis(2-methylpropionitrile) (AIBN) was purified by recrystallization from methanol. Deuterated NMR solvents were purchased from Cambridge Isotope Laboratories (CIL) and used as received. COE-ol was synthesized using a reported method. ${ }^{1}$ Sodium 4-styrenesulfonyl(trifluoromethylsulfonyl)imide was prepared via a literature procedure, where $\mathrm{K}_{2} \mathrm{CO}_{3}$ was replaced with $\mathrm{Na}_{2} \mathrm{CO}_{3}$ to provide the sodium salt instead of potassium salt. ${ }^{2}$

Synthesis of FAST $\mathrm{Na}^{+}$salt $\boldsymbol{A}$ on the 20-g scale

Pentafluorobenzene sulfonyl chloride $(19.1 \mathrm{~g}, 82.9 \mathrm{mmol})$ was dissolved in acetonitrile $(20 \mathrm{~mL})$. In a roundbottom flask, trifluoromethane sulfonamide $(10.9 \mathrm{~g}, 73.1 \mathrm{mmol})$ was dissolved in acetonitrile $(250 \mathrm{~mL})$ with $40 \mathrm{~mL} \mathrm{~N}$-methyl morpholine. (Note: use of triethylamine, pyridine, or $\mathrm{Na}_{2} \mathrm{CO}_{3}$ in place of $N$-methyl morpholine led to large amounts of side products.) The sulfonyl chloride solution was slowly added to the sulfonamide at $0{ }^{\circ} \mathrm{C}$ over a period of $45 \mathrm{~min}$. The reaction was slowly warmed to room temperature overnight, before being quenching by aqueous $\mathrm{HCl}(1 \mathrm{M})$. The mixture was dissolved in ethyl acetate and washed with dilute $\mathrm{HCl}$ and brine 3 times. The organic layer was dried over $\mathrm{Na}_{2} \mathrm{SO}_{4}$. Solvent evaporation provided the crude product as a solid or viscous liquid depending on the extent of solvent removal. In either case, addition of a minimum amount of dichloromethane and sonication for 10 minutes provided a suspension of solid product, which can be isolated via filtration. This process of suspension in dichloromethane, sonication, and filtration was repeated 3 times to yield $\mathbf{A}$ as a white solid in $\mathrm{Na}^{+}$salt form $(21.7 \mathrm{~g}, 54.1 \mathrm{mmol}$, yield $=74 \%)$. The soluble fraction in dichloromethane can be further purified by flash column chromatography using hexanes : acetone $=2: 1(\mathrm{v}: \mathrm{v})$ as the eluent if desired. ${ }^{19} \mathrm{~F}$ NMR $\left(\mathrm{d}_{6}\right.$-acetone, ppm, $\delta):-79.76,-138.41,-153.75,-164.73$.

\section{Synthesis of $\boldsymbol{A}-\boldsymbol{N}$}

$2 \mathrm{~mL}$ (20.2 mmol) of piperidine was combined with $2.6 \mathrm{~g}(6.5 \mathrm{mmol}) \mathbf{A}$ in $18 \mathrm{~mL}$ acetonitrile. $3 \mathrm{~mL}(21.5$ $\mathrm{mmol}$ ) triethylamine were added to the solution. The reaction was stirred at room temperature for $12 \mathrm{~h}$ before being quenched by $1 \mathrm{M}$ aqueous solution of $\mathrm{HCl}$. The reaction mixture was dissolved in ethyl acetate and washed with dilute $\mathrm{HCl}$ /water and then brine. After drying with $\mathrm{Na}_{2} \mathrm{SO}_{4}$ and concentrating under vacuum, the mixture was purified by column chromatography (hexanes/acetone) to yield a pale-yellow product $(2.8 \mathrm{~g}, 6.0 \mathrm{mmol}$, yield $=92 \%) .{ }^{19} \mathrm{~F}$ NMR $\left(\mathrm{d}_{6}\right.$-acetone, ppm, $\left.\delta\right):-79.67,-141.24,-153.54$.

\section{Synthesis of $\boldsymbol{A}-\boldsymbol{O}$}

$740 \mathrm{mg}$ (5.9 mmol) COE-ol and $2.35 \mathrm{~g}(5.9 \mathrm{mmol})$ A were dissolved in anhydrous dimethylformamide. $\mathrm{NaH}(60 \%$ in oil, $500 \mathrm{mg}, 12.5 \mathrm{mmol})$ was slowly added to the solution at room temperature. After $12 \mathrm{~h}$, the reaction was quenched by acetic acid. The mixture was dissolved in ethyl acetate and washed with brine three times. The organic phase was dried and concentrated. After column chromatography (hexanes/acetone), the product $(2.12 \mathrm{~g}$, yield $=71 \%)$ was obtained as a white solid. ${ }^{1} \mathrm{H}$ NMR $\left(\mathrm{d}_{6}\right.$-acetone, ppm, $\delta): 5.58(\mathrm{~m}, 2 \mathrm{H}), 4.49(\mathrm{~m}, 1 \mathrm{H}), 2.37(\mathrm{~m}, 1 \mathrm{H}), 2.22-1.90(\mathrm{~m}, 6 \mathrm{H}), 1.68(\mathrm{~m}, 2 \mathrm{H}), 1.45(\mathrm{~m}, 1 \mathrm{H}) .{ }^{13} \mathrm{C}$

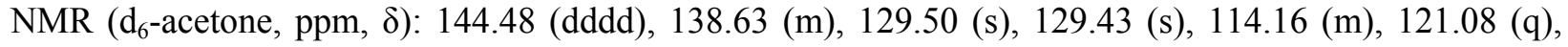


$118.64(\mathrm{t}), 87.16(\mathrm{~s}), 34.16(\mathrm{~s}), 33.43(\mathrm{~s}), 25.15(\mathrm{~s}), 24.58(\mathrm{~s}), 21.83$ (s). ${ }^{19} \mathrm{~F}$ NMR (d $\mathrm{d}_{6}$-acetone, ppm, $\left.\delta\right)$ : $79.35,-140.02,-157.99$.

\section{Synthesis of $\mathbf{A - O O O}$}

$1.22 \mathrm{~g}$ (2.4 mmol) A-O were dissolved in dry isopropanol ( $5 \mathrm{~mL}) .250 \mathrm{mg} \mathrm{NaH}(60 \%$ in oil, $6.3 \mathrm{mmol})$ were slowly added. The solution was stirred at room temperature for $15 \mathrm{~h}$ and then at $60^{\circ} \mathrm{C}$ for $5 \mathrm{~h}$, before being quenched by $1 \mathrm{~mL}$ of acetic acid. Column chromatography (hexanes:acetone from $4: 1$ to $3: 1$ ) provided the product as a white solid $(1.01 \mathrm{~g}, 1.7 \mathrm{mmol}$, yield $=72 \%) .{ }^{1} \mathrm{H}$ NMR $\left(\mathrm{d}_{6}\right.$-acetone, $\left.\mathrm{ppm}, \delta\right): 5.66$ $(\mathrm{m}, 2 \mathrm{H}), 4.72($ hept, $2 \mathrm{H}), 4.41(\mathrm{~m}, 1 \mathrm{H}), 1.40-2.50(\mathrm{~m}, 10 \mathrm{H}), 1.30(\mathrm{~d}, 12 \mathrm{H}) .{ }^{13} \mathrm{C}$ NMR $\left(\mathrm{d}_{6}\right.$-acetone, ppm, $\left.\delta\right)$ : 144.27 (dd), 143.13 (dd), 137.60 (t), 129.63 (s), 129.34 (s), 128.94 (s), 120.44 (q), 85.91 (s), 77.61 (s), $34.06(\mathrm{~s}), 33.22$ (s), 25.23 (s), $24.78(\mathrm{~s}), 21.98(\mathrm{~s}), 21.41(\mathrm{~s}) .{ }^{19} \mathrm{~F}$ NMR (d ${ }_{6}$-acetone, ppm, $\left.\delta\right):-79.05,-147.03$.

\section{Synthesis of $\boldsymbol{A}-\mathrm{NO}$}

$3.4 \mathrm{~g}$ (7.3 mmol) A-N were dissolved in $25 \mathrm{~mL}$ of dry dimethylformamide, together with $810 \mathrm{mg}$ (6.4 $\mathrm{mmol}$ ) COE-ol. To the solution were slowly added $412 \mathrm{mg} \mathrm{NaH}$ (60\% in oil, $10.3 \mathrm{mmol})$. The reaction was stirred at room temperature for $24 \mathrm{~h}$ before being quenched by acetic acid. The product was obtained as a pale-yellow solid $(3.8 \mathrm{~g}, 6.6 \mathrm{mmol}$, yield $=91 \%)$ after flash column chromatography (hexanes : acetone $=$ 3:1). 1H NMR (d3-acetonitrile, ppm, $\delta$ ): 5.66 (m, 2H), 4.51 (m, 1H), 3.24 (broad, 4H), 1.40-2.50 (m, 16H). ${ }^{13} \mathrm{C}$ NMR (d $\mathrm{d}_{6}$-acetone, ppm, $\delta$ ): 147.01 (ddd), 145.35 (ddd), $141.31(\mathrm{ddd}), 140.28(\mathrm{dt}), 133.01(\mathrm{t}), 129.78$ (s), 129.16 (s), 121.56 (d), 120.39 (q), 86.61 (d), 51.97 (t), 33.54 (s), 32.94 (s), 26.37 (s), 25.13 (s), 24.47 (s), $23.87(\mathrm{~s}), 22.31(\mathrm{~s}) .{ }^{19} \mathrm{~F}$ NMR (d ${ }_{6}$-acetone, ppm, $\delta$ ): -79.20, -139.28, -153.95.

\section{Synthesis of $\boldsymbol{A}-\mathbf{N O O}$}

$850 \mathrm{mg}$ (1.5 mmol) A-NO were dissolved in $5 \mathrm{~mL}$ of anhydrous isopropanol. At room temperature, 200 $\mathrm{mg} \mathrm{NaH}(60 \%$ in oil, $5.0 \mathrm{mmol})$ were slowly added. Then, the mixture was heated to $60^{\circ} \mathrm{C}$ for $24 \mathrm{~h}$. After quenching with acetic acid, $770 \mathrm{mg}$ product $(1.3 \mathrm{mmol}$, yield $=85 \%)$ was obtained after flash column chromatography using hexanes/acetone (3:1) as the eluent. ${ }^{1} \mathrm{H}$ NMR (d6-acetone, ppm, $\left.\delta\right): 5.49(\mathrm{~m}, 2 \mathrm{H})$, 4.51 (hept, 1H), $4.40(\mathrm{tt}, 1 \mathrm{H}), 3.05$ (broad, $4 \mathrm{H}), 2.20-1.30(\mathrm{~m}, 15 \mathrm{H}), 1.16(\mathrm{~d}, 6 \mathrm{H}) .{ }^{13} \mathrm{C}$ NMR (d -acetone, $^{-}$ ppm, $\delta$ ): 148.37 (dd), 145.98 (dd), 140.75 (dd), 140.62 (dd), 132.60 (t), 129.85 (s), 129.18 (s), 127.18 (s), 120.44 (q), 85.97 (d), 77.45 (d), 52.11 (t), 33.50 (s), 32.85 (s), 26.47 (s), 25.22 (s), 24.75 (s), 23.98 (s), 22.39 (s), 21.46 (d). ${ }^{19} \mathrm{~F}$ NMR (d -acetone, $^{\text {ppm, } \delta): ~-79.10, ~-140.95, ~-141.51 . ~}$

\section{Synthesis of $\boldsymbol{A}-\boldsymbol{O N}$}

$850 \mathrm{mg}(1.7 \mathrm{mmol}) \mathbf{A}-\mathbf{O}$ were dissolved in $5 \mathrm{~mL}$ acetonitrile. $0.5 \mathrm{~mL}(5.1 \mathrm{mmol})$ of piperidine and $1.5 \mathrm{~mL}$ of triethylamine $(10.8 \mathrm{mmol})$ were added. The solution was heated to $60{ }^{\circ} \mathrm{C}$ for $48 \mathrm{~h}$ before removing all the volatile components under vacuum. Then, the mixture was dissolved in a minimum amount of water, and $10 \mathrm{~mL}$ aqueous $\mathrm{HCl}$ solution $(3.0 \mathrm{M})$ was added. The precipitates were collected and purified by flash column chromatography (hexanes/acetone). Protonated zwitterion A-ON $\mathbf{N}^{+}$was obtained $(865 \mathrm{mg}$, yield $=$ 94\%). Dissolving A-ON ${ }^{+}$in ethyl acetate $(30 \mathrm{~mL})$ and washing with $\sim 4$ equivalents of aqueous $\mathrm{NaOH}(1.0$ M) gave the target product in quantitative yield. ${ }^{1} \mathrm{H}$ NMR $\left(\mathrm{d}_{6}\right.$-acetone, $\left.\mathrm{ppm}, \delta\right): 5.58(\mathrm{~m}, 2 \mathrm{H}), 4.31(\mathrm{~m}, 1 \mathrm{H})$, 
2.89 (broad, 4H), $2.30(\mathrm{~m}, 1 \mathrm{H}), 2.20-1.30(\mathrm{~m}, 14 \mathrm{H}), 1.20$ (broad, $1 \mathrm{H}) .{ }^{13} \mathrm{C}$ NMR $\left(\mathrm{d}_{6}\right.$-acetone, ppm, $\left.\delta\right)$ : 152.84 (d), 145.06 (ddd), 143.61 (dd), 142.74 (ddd), 137.90 (m), 136.01 (dd), 129.62 (s), 129.34 (s), 127.80 (dd). ${ }^{19}$ F NMR (d ${ }_{6}$-acetone, ppm, $\delta$ ): $-79.35,-140.02,-157.99$.
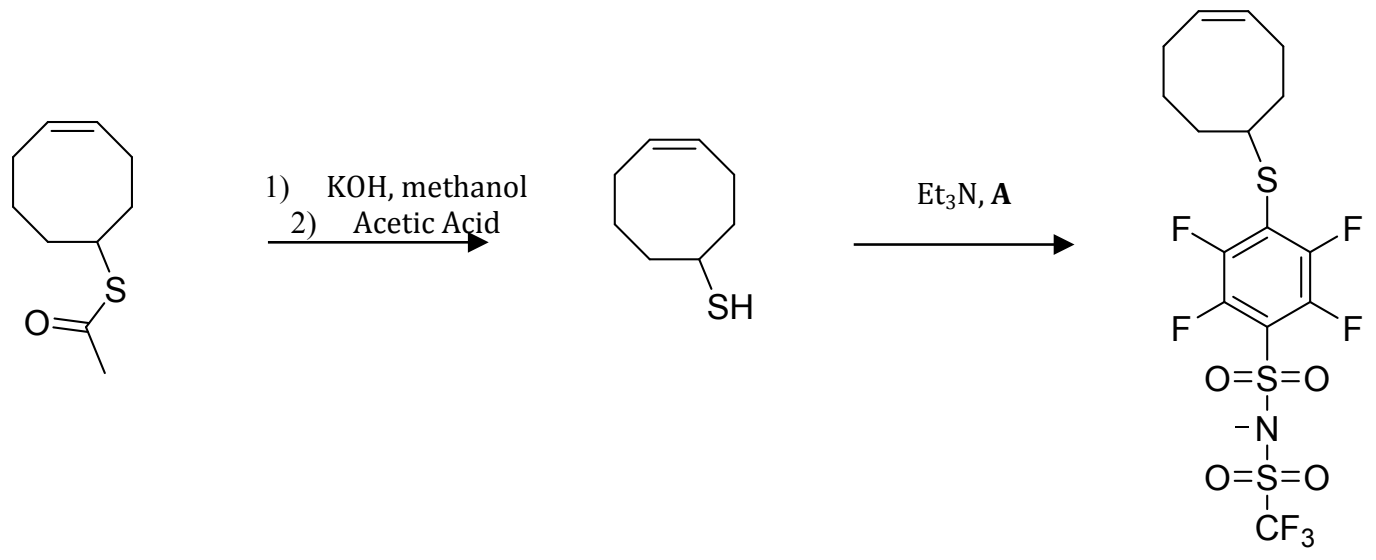

Scheme S2. Synthetic procedure of A-S monomer.

\section{Synthesis of COE-S-ester}

In a flask were added $3 \mathrm{~g}(27.7 \mathrm{mmol})$ cyclooctadiene, $1.8 \mathrm{~g}(23.6 \mathrm{mmol})$ thioacetic acid, and a few crystals of AIBN. (Note: the reaction is exothermic and auto-accelerating. Take caution!) After stirring in a water bath at room temperature overnight, the mixture was purified by flash column chromatography (hexanes/dichloromethane) and then distilled under reduced pressure to yield a pale-yellow oil (3.1 g, yield $=69 \%) .{ }^{1} \mathrm{H}$ NMR $(\mathrm{CDCl} 3, \mathrm{ppm}, \delta): 5.56(\mathrm{~m}, 2 \mathrm{H}), 3.58(\mathrm{~m}, 1 \mathrm{H}), 2.27-2.37(\mathrm{~m}, 1 \mathrm{H}), 2.26(\mathrm{~s}, 3 \mathrm{H}), 2.14(\mathrm{~m}$, 3H), 1.55-1.88 (m, 6H). ${ }^{13} \mathrm{C} \mathrm{NMR} \mathrm{(CDCl3,} \mathrm{ppm,} \mathrm{\delta ):} 195.97$ (s), 131.36 (s), 129.35 (s), 43.08 (s), 34.92 (s), $34.09(\mathrm{~s}), 30.55(\mathrm{~s}), 27.48(\mathrm{~s}), 25.56(\mathrm{~s}), 24.76(\mathrm{~s})$.

\section{Synthesis of $\boldsymbol{A}-\boldsymbol{S}$}

As shown in Scheme S2, $1.7 \mathrm{~g}(9.2 \mathrm{mmol})$ of COE-S-ester were dissolved in $20 \mathrm{~mL}$ methanol. While this solution was stirred at $60{ }^{\circ} \mathrm{C}, 1.55 \mathrm{~g}(27.7 \mathrm{mmol}) \mathrm{KOH}$ were added in portions. The reaction was allowed to continue for $1 \mathrm{~h}$ before being quenched by $2.0 \mathrm{~mL}$ acetic acid $(34.9 \mathrm{mmol})$. Then, $2.0 \mathrm{~g}(5.0 \mathrm{mmol}) \mathrm{A}$ and $3 \mathrm{~mL}(40.8 \mathrm{mmol})$ triethylamine were added, and the mixture was stirred at $60^{\circ} \mathrm{C}$ for $12 \mathrm{~h}$. The reaction mixture was diluted with ethyl acetate and extracted first with brine, then $1 \mathrm{M} \mathrm{HCl} / \mathrm{H}_{2} \mathrm{O} 2$ times, and finally brine again. After drying over $\mathrm{Na}_{2} \mathrm{SO}_{4}$ and concentrating under vacuum, the product was further purified by flash column chromatography (hexanes/acetone) to yield a white solid (1.52 g, yield $=69 \%)$. ${ }^{1} \mathrm{H} \mathrm{NMR}$ $\left(\mathrm{d}_{6}\right.$-acetone, ppm, $\left.\delta\right): 5.68(\mathrm{~m}, 2 \mathrm{H}), 3.57(\mathrm{~m}, 1 \mathrm{H}), 1.35-2.50(\mathrm{~m}, 10 \mathrm{H}) .{ }^{13} \mathrm{C}$ NMR $\left(\mathrm{d}_{6}\right.$-acetone, ppm, $\left.\delta\right)$ : $146.53(\mathrm{~m}), 143.63(\mathrm{~m}), 130.03(\mathrm{~s}), 129.24(\mathrm{~s}), 124.84(\mathrm{t}), 120.30(\mathrm{q}), 117.09(\mathrm{t}), 47.25(\mathrm{t}), 35.31(\mathrm{~s}), 33.47$

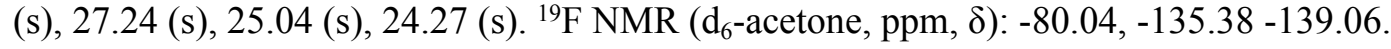


A representative procedure is shown here. $386 \mathrm{mg}$ (x mmol) A-NO were dissolved in $3.5 \mathrm{~mL}$ methanol (ethanol was used in a few cases) and the solution was sparged with $\mathrm{N}_{2}$ for $5 \mathrm{~min} .3 .6 \mathrm{mg}$ (x mmol) Grubbs $2^{\text {nd }}$ generation catalyst were dissolved in $1 \mathrm{~mL}$ chloroform (dichloromethane was used in a few cases) and the solution was sparged with $\mathrm{N}_{2}$ for 5 min before being transferred to the monomer solution. The reaction was stirred at room temperature for $12 \mathrm{~h}$. The polymer was isolated by removing the solvent.

\section{Synthesis of (Sox)'”}

$63 \mathrm{mg}$ (S)' (0.12 mmol repeat unit) were dissolved in $3 \mathrm{ml}$ acetonitrile. Then, $130 \mathrm{mg}$ ( $\sim 0.53 \mathrm{mmol}, 4.4$ equivalents per repeat unit) meta-chloroperoxybenzoic acid (70-75 wt \%) were added in 2 portions $(4 \mathrm{~h}$ between each). The reaction was stirred at room temperature overnight before being quenched by $10 \mathrm{~mL}$ $\mathrm{Na}_{2} \mathrm{~S}_{2} \mathrm{O}_{3}(2 \mathrm{M})$ in $\mathrm{H}_{2} \mathrm{O}$. The polymer was isolated by dialysis against aqueous solution of $\mathrm{LiCl}(\sim 0.1 \mathrm{M})$. The $\mathrm{LiCl}$ solution was changed at least 5 times ( 2 days), before switching to ultrapure water. The ultrapure water was changed at least 5 times ( 2 days), and then the polymer solution was lyophilized to isolate the polymer in lithium form.

\section{General hydrogenation procedure}

A representative procedure is as follows. $200 \mathrm{mg}$ of A-NO polymer were dissolved in $8 \mathrm{~mL}$ acetone (ethyl acetate was used in some cases). The solution was sparged with $\mathrm{N}_{2}$ for 10 min and under gentle $\mathrm{N}_{2}$ flow were added $102 \mathrm{mg} \mathrm{Pd} / \mathrm{C}(10 \mathrm{wt} \%)$. After using gentle vacuum to remove the majority of $\mathrm{N}_{2}$ and residual $\mathrm{O}_{2}$, the reaction was sealed with a rubber septum and $\mathrm{H}_{2}$ was introduced via a balloon with a needle. The reaction was stirred for $5 \mathrm{~h}$ and then sparged with $\mathrm{N}_{2}$ before being opened to air. The $\mathrm{Pd} / \mathrm{C}$ was removed by passing the solution through Celite (dried overnight at $120{ }^{\circ} \mathrm{C}$ before use). The polymer was isolated by removing the solvent under vacuum.

\section{General free radical polymerization procedure}

AIBN and the vinyl monomer, i.e. either sodium styrenesulfonate or sodium 4styrenesulfonyl(trifluoromethylsulfonyl)imide, were mixed in a ratio of 1:50 and dissolved in ethanol to a concentration of $200 \mathrm{mg} / \mathrm{mL}$. The clear solution was degassed by sparging with nitrogen for $15 \mathrm{~min}$. After being heated at $60^{\circ} \mathrm{C}$ for 15 hours, the polymer was purified by dialysis against ultrapure water for 2 days with the water being replaced for at least 5 times. After lyophilization, the product was obtained as a white solid.

\section{Polymer purification and ion exchange}

The polymer was dialyzed against an aqueous solution of $\operatorname{LiCl}(\sim 0.1 \mathrm{M})$ with a molecular weight cutoff $=$ $3000 \mathrm{~g} / \mathrm{mol}$. The $\mathrm{LiCl}$ solution was changed at least 5 times ( 2 days), before switching to ultrapure water. The ultrapure water was changed at least 5 times ( 2 days), and then the polymer solution was lyophilized to isolate the polymer in lithium form.

\section{Deprotonation of partially protonated (ON)}


(ON) was found to be partially protonated at the piperidine nitrogen atom after ion exchange. The material was dissolved in water and ethyl acetate to form a biphasic system. Then $\sim 2$ equivalents of $\mathrm{LiOH}$ (relative to the piperidine groups) were dissolved in a minimum amount of water and added to the mixture. The mixture was stirred vigorously for $10 \mathrm{~min}$ before isolating the organic phase. The fully lithiated polymer was isolated by removing residual solvent. It was observed that when partially protonated, the polymer can only be suspended in water (cloudy and opaque), while the deprotonated polymer can be easily dissolved in water and organic solvents. 


\section{S2. Theoretical calculations}

All calculations were performed employing the Gaussian 09 computational package. ${ }^{3}$ Geometries were optimized at the B3LYP/6-31G(d,p $)^{4,5}$ level of theory; ground states were verified by the absence of any imaginary frequency. Single point energy calculations were performed at the B3LYP/6-311++G(d,p) level of theory for oxidation energies $\left(\Delta \mathrm{G}_{\mathrm{ox}}\right)$ and dissociation free energies $\left(\Delta \mathrm{G}_{\mathrm{dis}}\right)$. The conductor-like polarizable continuum model (CPCM) ${ }^{6,7}$ was employed to capture the solvation effects. Electrochemical oxidative stability is estimated by oxidation energy calculations, which is the Gibbs free energy for the electrochemical oxidation reaction $\mathrm{M} \rightarrow \mathrm{M}^{+}+\mathrm{e}^{-}$in the solution (Dimethyl sulfoxide (DMSO) was selected as the universal solvent in the electrochemical oxidation energy calculations):

$$
\mathrm{G}_{\mathrm{Ox}}=\mathrm{G}\left(\mathrm{M}^{+}\right)-\mathrm{G}(\mathrm{M})
$$

In dissociation free energies calculations, diethyl ether was selected as the implicit solvent, and the dielectric constant of the implicit solvent was set to 7.2 to mimic the solvation environment of 1,2dimethoxyethane (DME), a short-chain analogue of PEO. The likelihood of salt dissociation was estimated by the Gibbs free energy of the reaction $\mathrm{LiA} \rightarrow \mathrm{Li}^{+}+\mathrm{A}^{-}$, which is taken to be the dissociation free energy in the solution:

$$
\Delta \mathrm{G}_{\mathrm{dis}}=\mathrm{G}\left(\mathrm{Li}^{+}\right)+\mathrm{G}\left(\mathrm{A}^{-}\right)-\mathrm{G}(\mathrm{LiA})
$$

$\mathrm{G}\left(\mathrm{Li}^{+}\right)$is approximated using the solvation of $\mathrm{Li}^{+}$in DME, more specifically,

$$
\mathrm{G}\left(\mathrm{Li}^{+}\right)=\mathrm{G}_{\text {gas }}\left(\mathrm{Li}^{+}\right)+\Delta \mathrm{G}_{\mathrm{sol}}\left(\mathrm{Li}^{+}\right)+\mathrm{RT} \ln (24.46)
$$

where $\Delta \mathrm{G}_{\mathrm{sol}}\left(\mathrm{Li}^{+}\right)$is the solvation energy of $\mathrm{Li}^{+}$in $\mathrm{DME}$, and its value was taken from a computational study, ${ }^{8}$ where three explicit DME molecules were considered. $\mathrm{G}_{\text {gas }}\left(\mathrm{Li}^{+}\right)$is the gas-phase free energy of $\mathrm{Li}^{+}$and its value was computed using the same methods/basis sets. The term $\mathrm{RT} \ln (24.46)$ converts a gasphase reference state of $1 \mathrm{~atm}$ to a liquid-phase reference state of $1 \mathrm{M}$. We note that the values of $\mathrm{G}\left(\mathrm{Li}^{+}\right)$ obtained using this method are similar to those directly computed using an implicit solvation model. 


\section{S3. Electrochemical stability test in solution state}

The polymer samples were vacuum-dried at $75^{\circ} \mathrm{C}$ overnight before being transferred into an Argon glove box $\left(\mathrm{H}_{2} \mathrm{O}<0.1 \mathrm{ppm}, \mathrm{O}_{2}<0.1 \mathrm{ppm}, \mathrm{MBraun}, \mathrm{USA}\right)$ without exposure to the atmosphere. The oxidative stability of the polymers was studied in electrochemical cells consisting of a Lithium foil $(\mathrm{D}=15 \mathrm{~mm}$, Chemetall, Germany), $90 \mu \mathrm{L}$ of $0.02 \mathrm{M}$ (monomer concentration) polymer sample in propylene carbonate $\left(\mathrm{H}_{2} \mathrm{O}<20\right.$ ppm by Karl Fischer titration, BASF), one piece of glass fiber separator $\left(\mathrm{D}=18 \mathrm{~mm}\right.$, Whatman ${ }^{\circledR}$, Grade GF/A), and a 304 stainless steel mesh as current collector $(\mathrm{D}=12.7 \mathrm{~mm})$. In each electrochemical stability test, after holding the cell at open circuit voltage for $2 \mathrm{~h}$, a series of potentials were applied sequentially for $3 \mathrm{~h}$ each: $3.0,3.2,3.4,3.6,3.8,4.0,4.2,4.4$, and $4.5 \mathrm{~V}$; the current response was recorded throughout the test. All electrochemical tests were conducted employing a VMP3 potentiostat (BioLogic Science Instruments). 


\section{S4. Conductivity measurement}

A predetermined weight of polymer sample (in lithium form) was mixed with PEO in tetrahydrofuran/acetonitrile ( $\mathrm{v}: \mathrm{v}=1: 1$, ethanol was used for PHS and $\mathbf{P H S O}$ ). A small fraction of the solution was dried under vacuum, which was then used for determining the exact value of $[\mathrm{EO}] /[\mathrm{Li}]$ by ${ }^{1} \mathrm{H}$ $\mathrm{NMR}$, based on the assumption that each repeat unit of the anionic monomer corresponds to one $\mathrm{Li}^{+}$cation. The rest of the solution was cast onto a Teflon sheet and dried at room temperature. The solid blend was further dried at $80^{\circ} \mathrm{C}$ under vacuum before being subjected to impedance measurements.

The impedance measurements were conducted using electrochemical cells consisting of polymer electrolytes sandwiched between two stainless steel blocking electrodes, where the polymer electrolytes contained $20 \mathrm{kDa}$ PEO and polymer sample blends at various [EO] to [Li] ratios. The conductivity was studied with electrochemical impedance spectroscopy (EIS, VMP3, Bio-Logic Science Instruments) over the frequency range of $1 \mathrm{MHz}$ and $0.1 \mathrm{~Hz}$ at a voltage amplitude of $10 \mathrm{mV}$. The bulk electrolyte conductivity, $\sigma$, is estimated from the bulk electrolyte resistance, R, obtained in the EIS measurement according to the equation

$$
\sigma=\frac{1 d}{R A}
$$

where $d$ is the thickness of the polymer electrolyte and $\mathrm{A}$ is the cross-sectional area of tested sample. The tests were done by first equilibrating the samples at $80^{\circ} \mathrm{C}$ to remove the thermal history; samples were then equilibrated at each temperature for at least 2 hours.

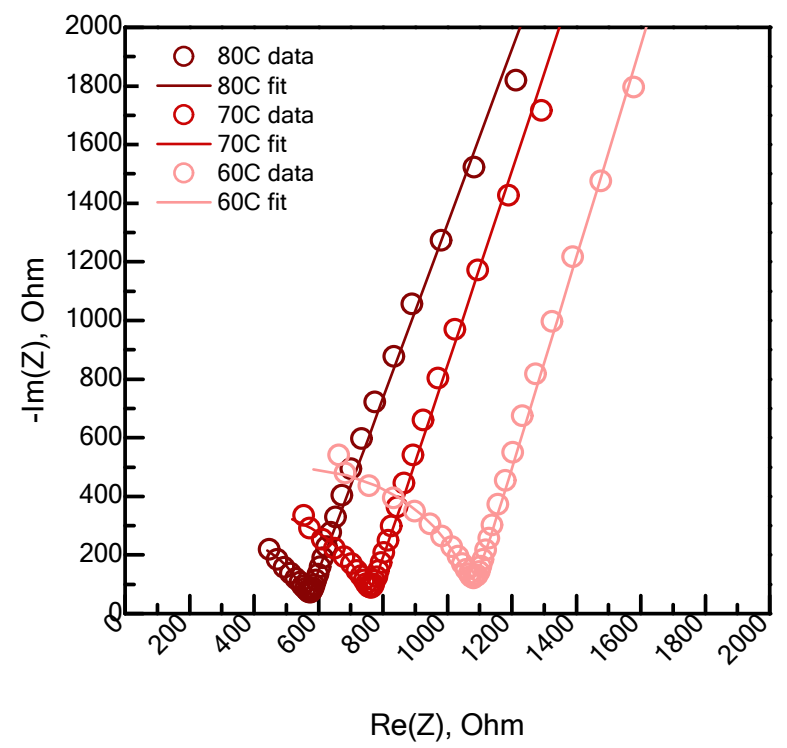

Figure S1. Representative Nyquist plot of impedance data of PEO + (NO) $\left([\mathrm{EO}] /\left[\mathrm{Li}^{+}\right]=57\right)$. 


\section{S5. NMR characterization}

NMR spectra were recorded on a Bruker AVANCE-400 MHz NMR spectrometer, or VARIAN Inova$300 \mathrm{MHz}$ NMR spectrometer. Spectra were analyzed on MestReNova NMR software. Chemical shifts are expressed in parts per million (ppm).
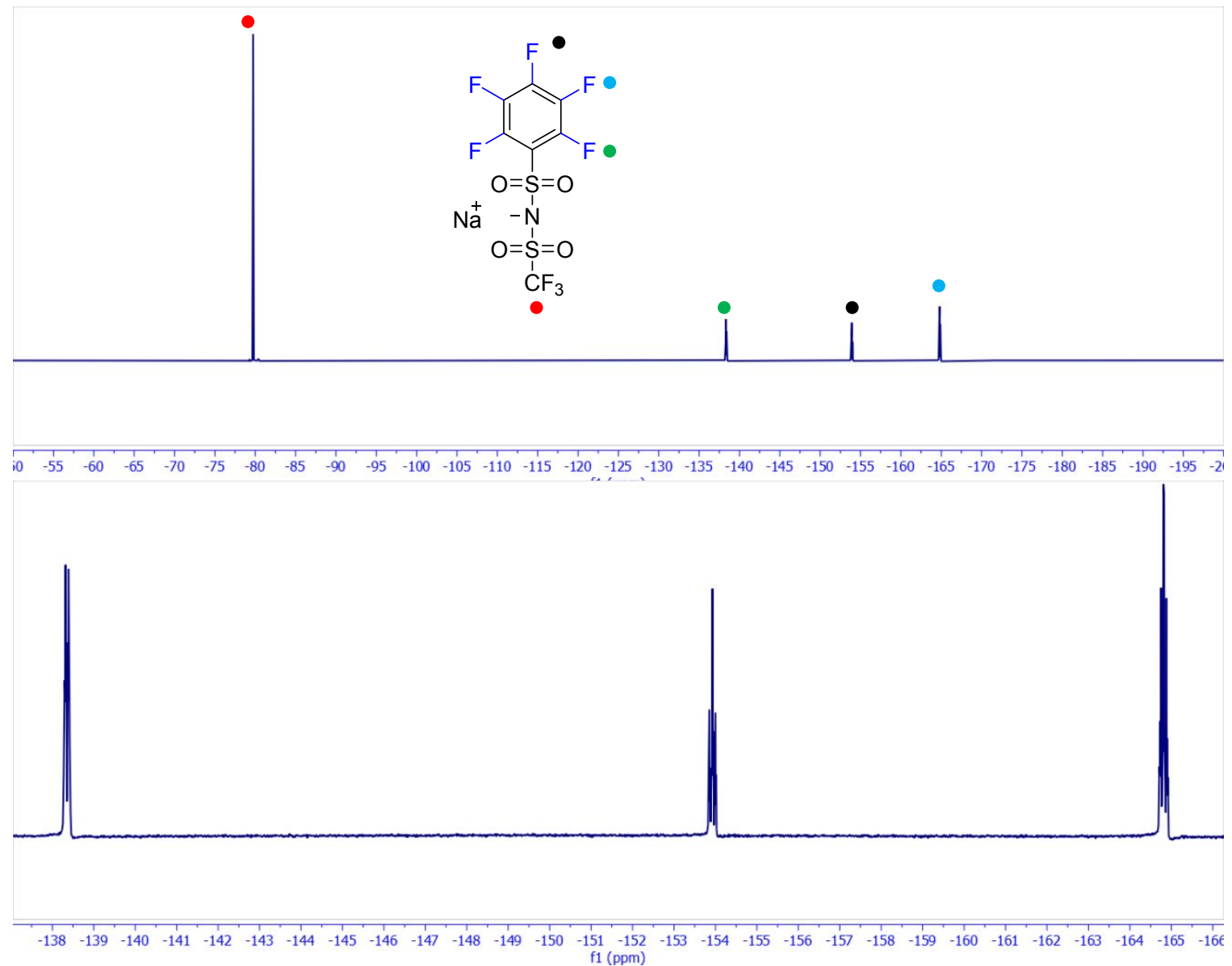

Figure S2. ${ }^{19} \mathrm{~F}$ NMR spectrum of $\mathbf{A}$ in $\mathrm{d}_{6}$-acetone (top is the full spectrum and bottom is zoomed view). 

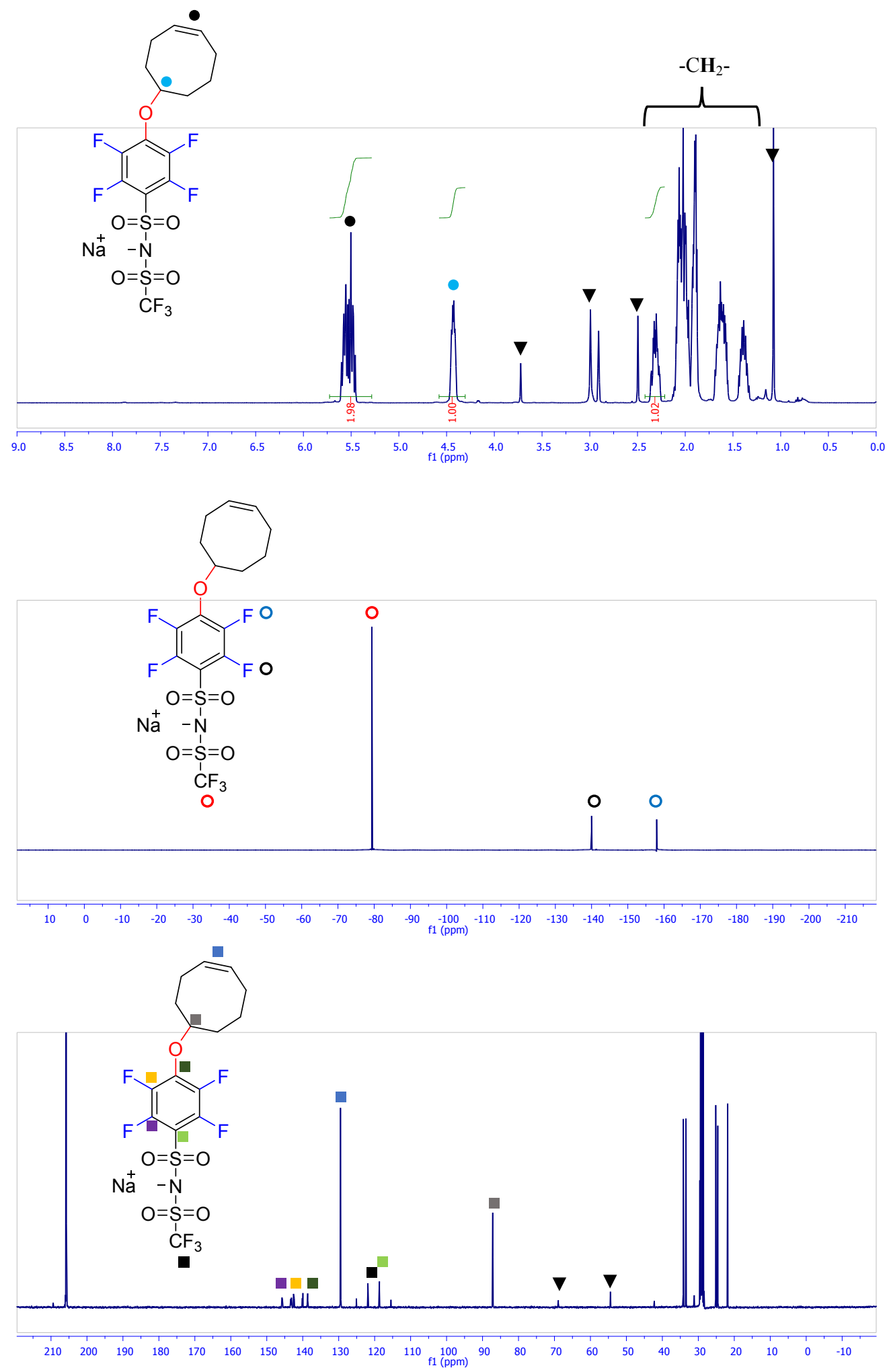

Figure S3. ${ }^{1} \mathrm{H}$ (top, peak at $\sim 2.8 \mathrm{ppm}$ is water and peaks of diacetone alcohol are assigned with $\boldsymbol{\nabla}$ ), ${ }^{19} \mathrm{~F}$ (middle) and ${ }^{13} \mathrm{C}$ (bottom) NMR spectra for $\mathbf{A}-\mathbf{O}$ in $\mathrm{d}_{6}$-acetone. 

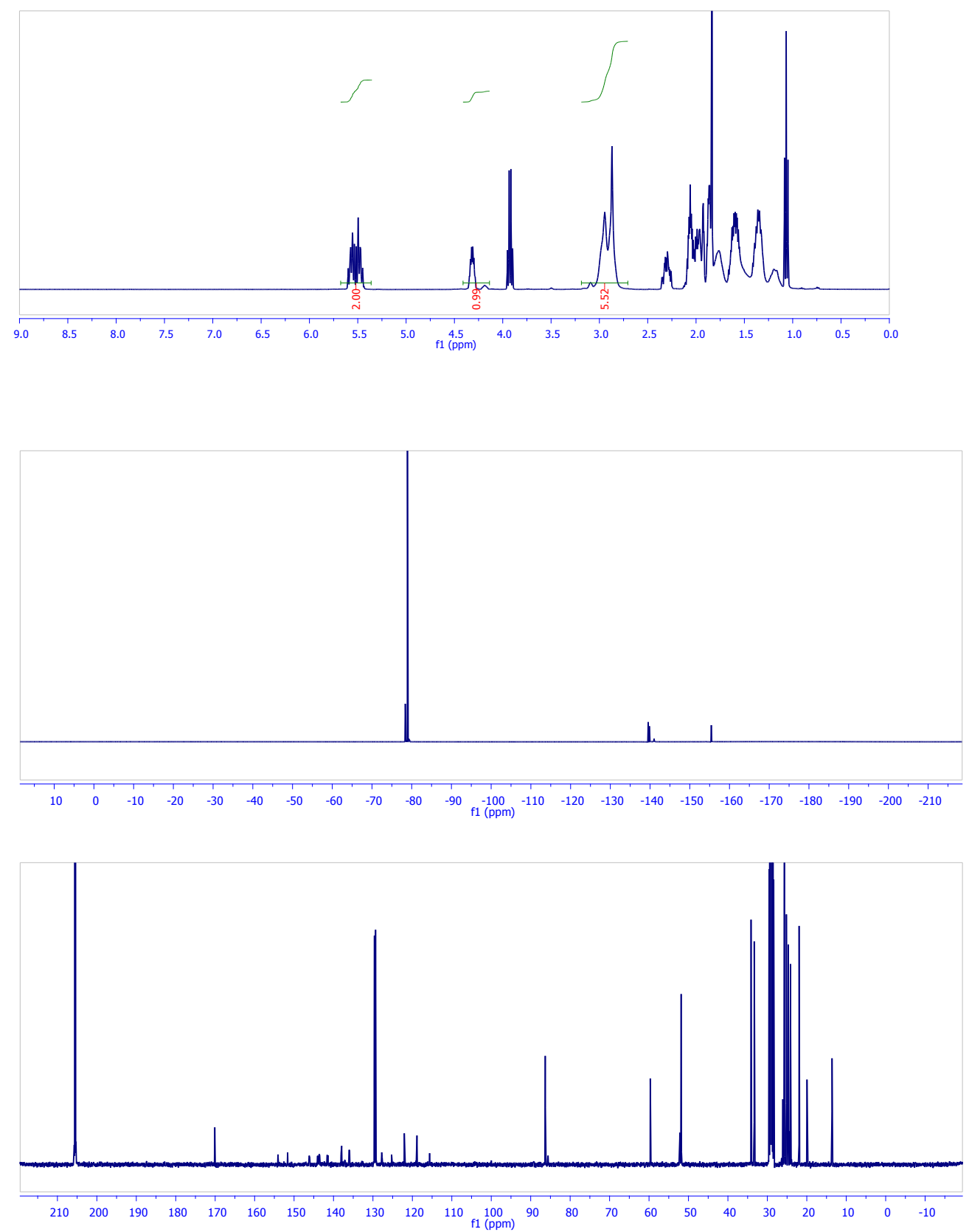

Figure S4. ${ }^{1} \mathrm{H}$ (top), ${ }^{19} \mathrm{~F}$ (middle) and ${ }^{13} \mathrm{C}$ (bottom) NMR spectra for A-ON in $\mathrm{d}_{6}$-acetone, partially protonated. 

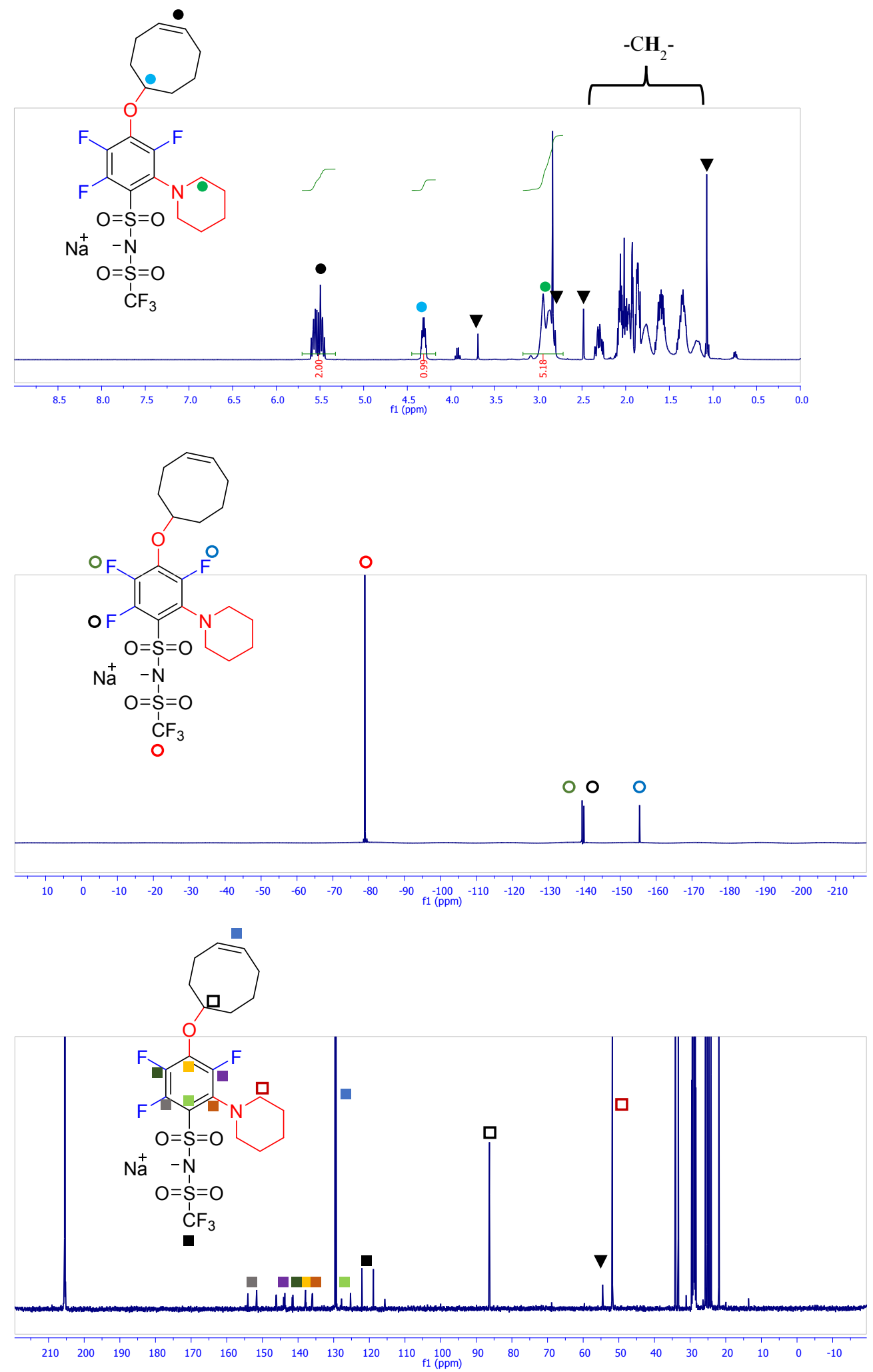

Figure S5. ${ }^{1} \mathrm{H}$ (top), ${ }^{19} \mathrm{~F}$ (middle) and ${ }^{13} \mathrm{C}$ (bottom) NMR spectra for A-ON in $\mathrm{d}_{6}$-acetone, fully deprotonated. Peaks of diacetone alcohol are marked with $\boldsymbol{\nabla}$. 

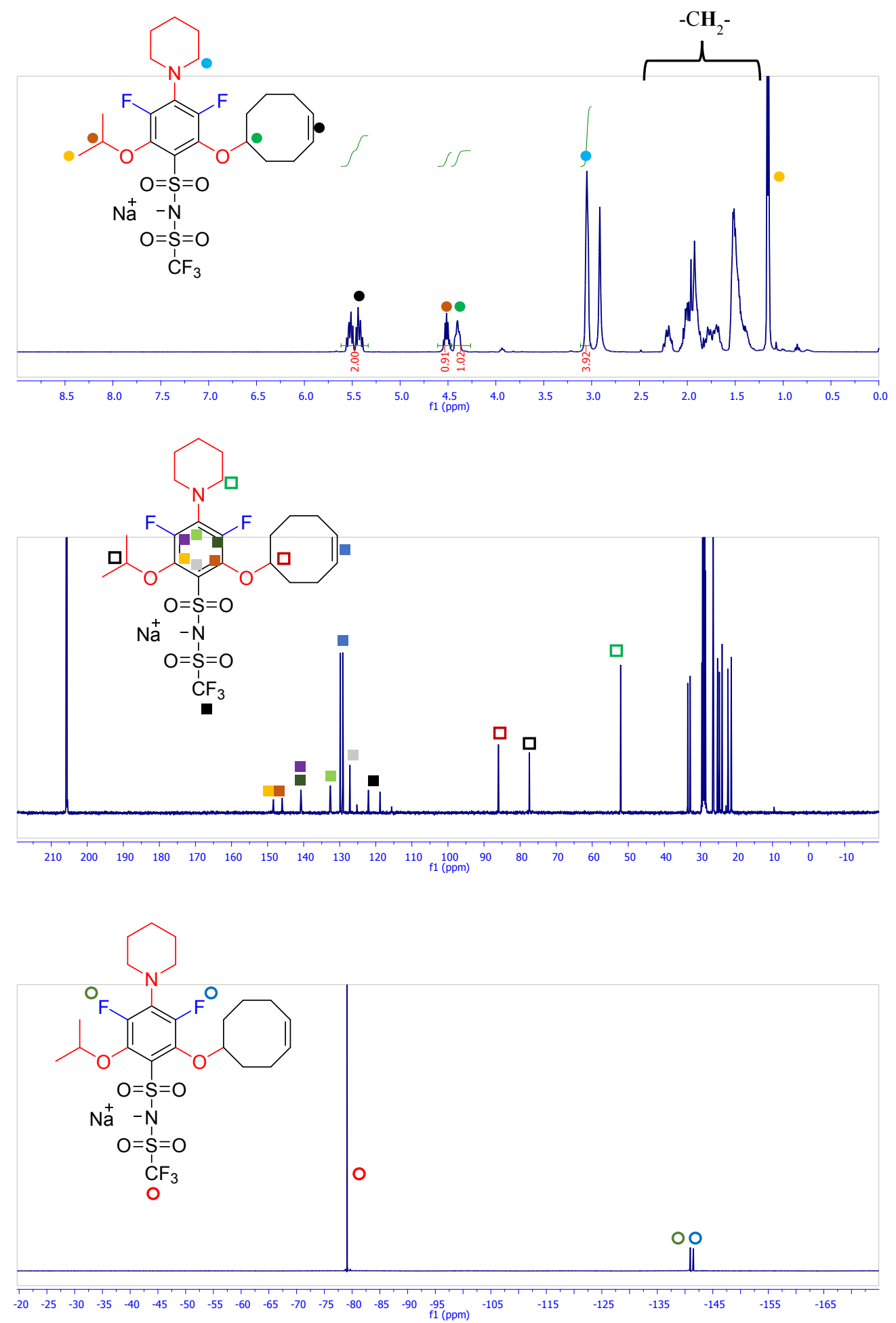

Figure S6. ${ }^{1} \mathrm{H}$ (top), ${ }^{19} \mathrm{~F}$ (middle) and ${ }^{13} \mathrm{C}$ (bottom) NMR spectra for A-NOO in $\mathrm{d}_{6}$-acetone 

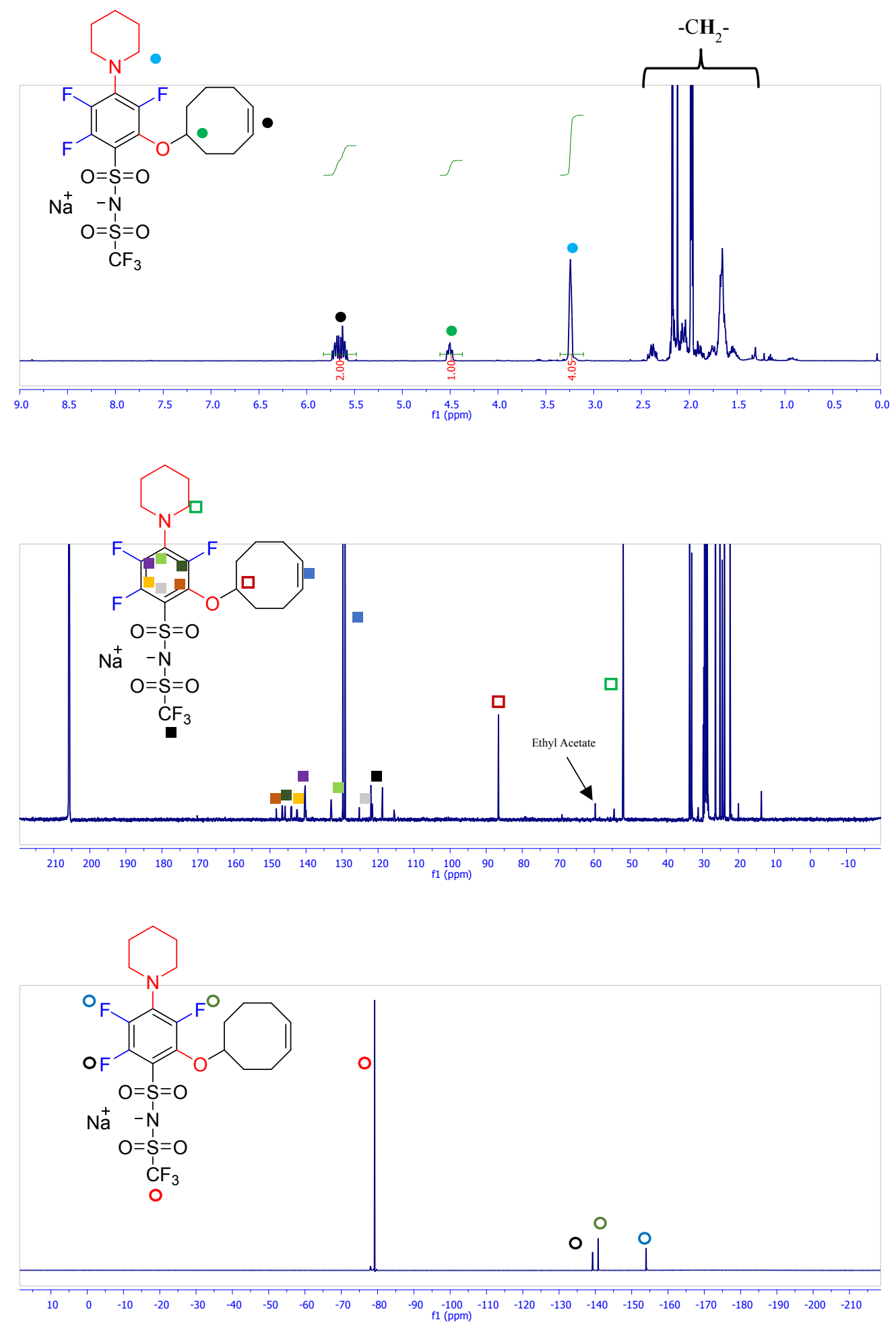

Figure S7. ${ }^{1} \mathrm{H}$ (top, in $\mathrm{d}_{3}$-acetonitrile), ${ }^{19} \mathrm{~F}$ (middle, in $\mathrm{d}_{6}$-acetone) and ${ }^{13} \mathrm{C}$ (bottom, in $\mathrm{d}_{6}$-acetone) NMR spectra for A-NO. 

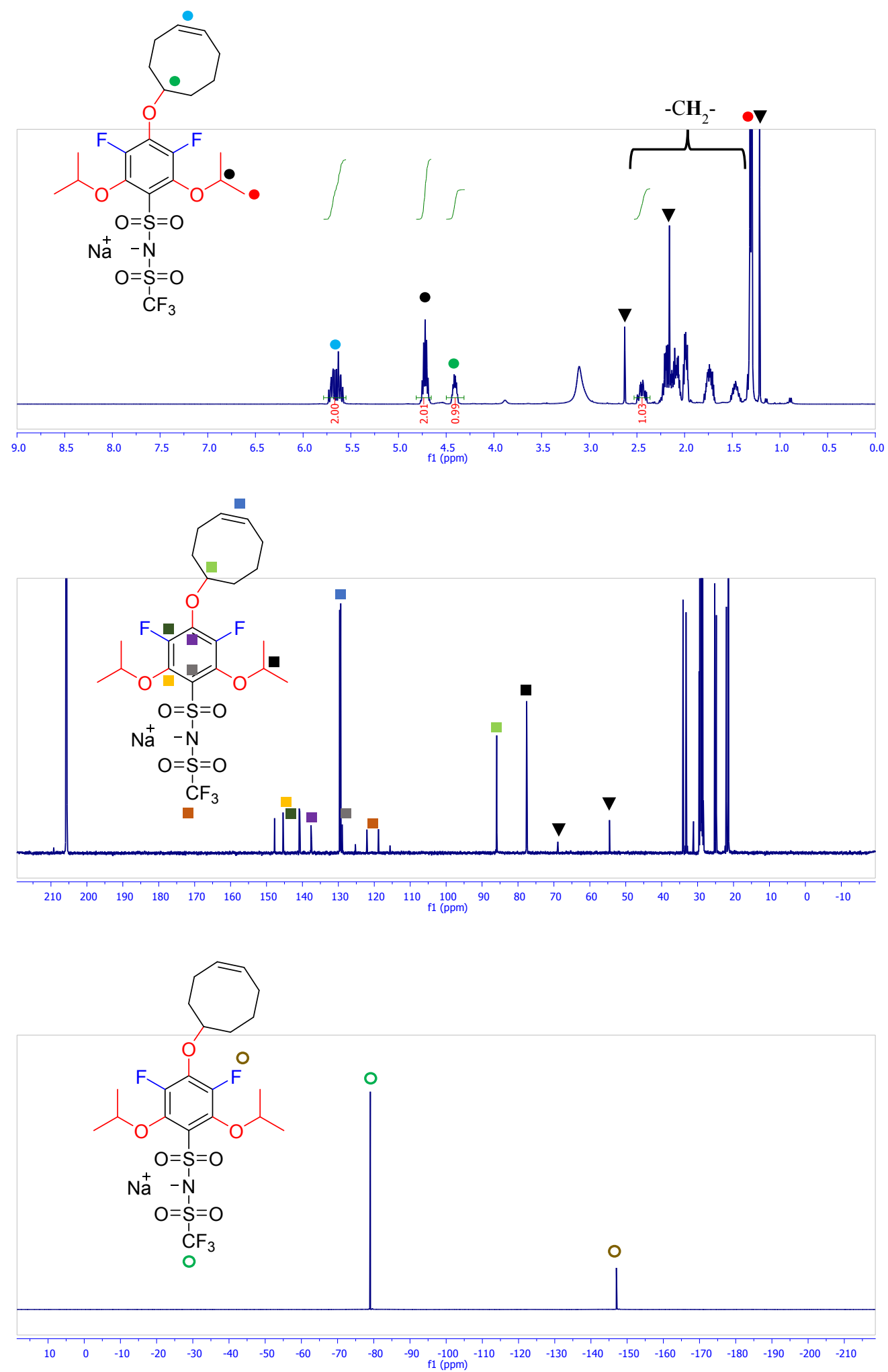

Figure S8. ${ }^{1} \mathrm{H}$ (top), ${ }^{19} \mathrm{~F}$ (middle) and ${ }^{13} \mathrm{C}$ (bottom) NMR spectra for A-OOO in $\mathrm{d}_{6}$-acetone. Peaks of diacetone alcohol are marked with $\boldsymbol{\nabla}$. 

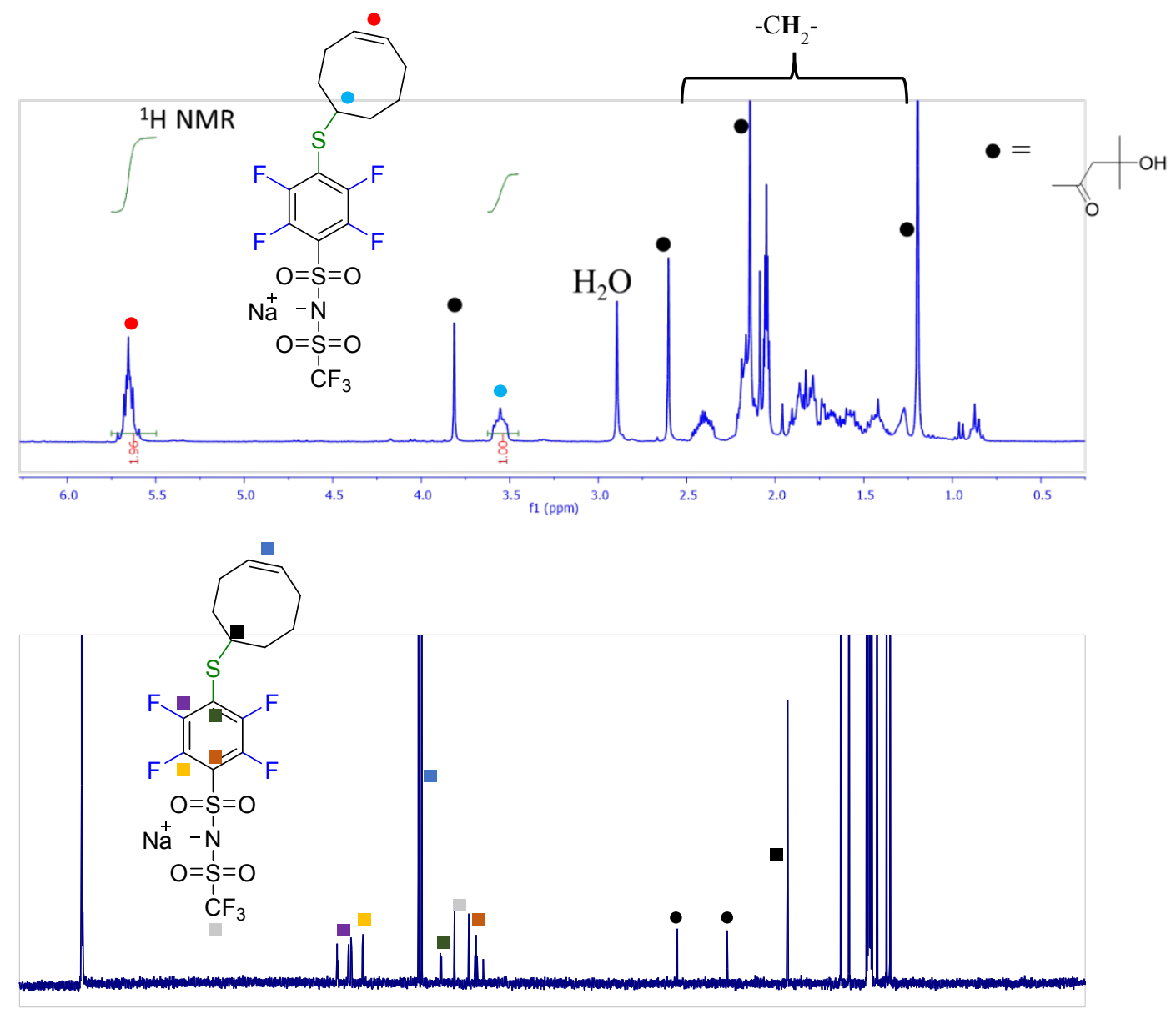

$\begin{array}{lllllllllllllllllllllllllll}210 & 200 & 190 & 180 & 170 & 160 & 150 & 140 & 130 & 120 & 110 & 100 & 90 & 10 & 70 & 60 & 50 & 40 & 30 & 20 & 10 & 0 & -10\end{array}$

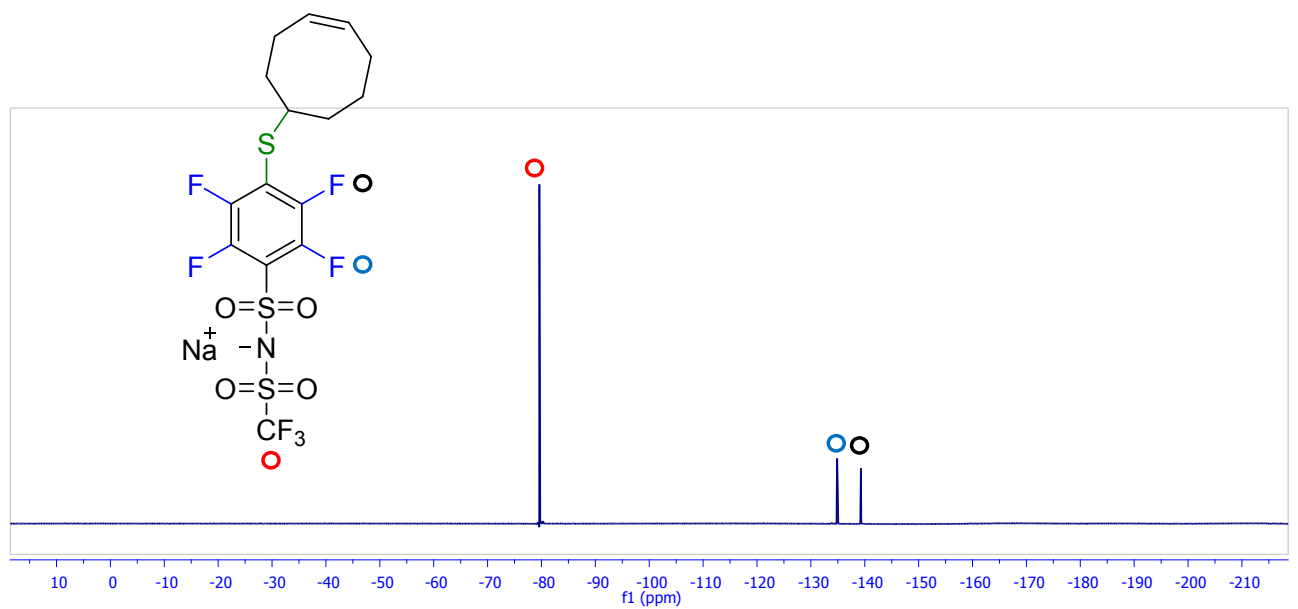

Figure S9. ${ }^{1} \mathrm{H}$ (top), ${ }^{19} \mathrm{~F}$ (middle) and ${ }^{13} \mathrm{C}$ (bottom) NMR spectra for $\mathbf{A}-\mathbf{S}$ in $\mathrm{d}_{6}$-acetone. Peaks of diacetone alcohol are marked with $\bullet$. 

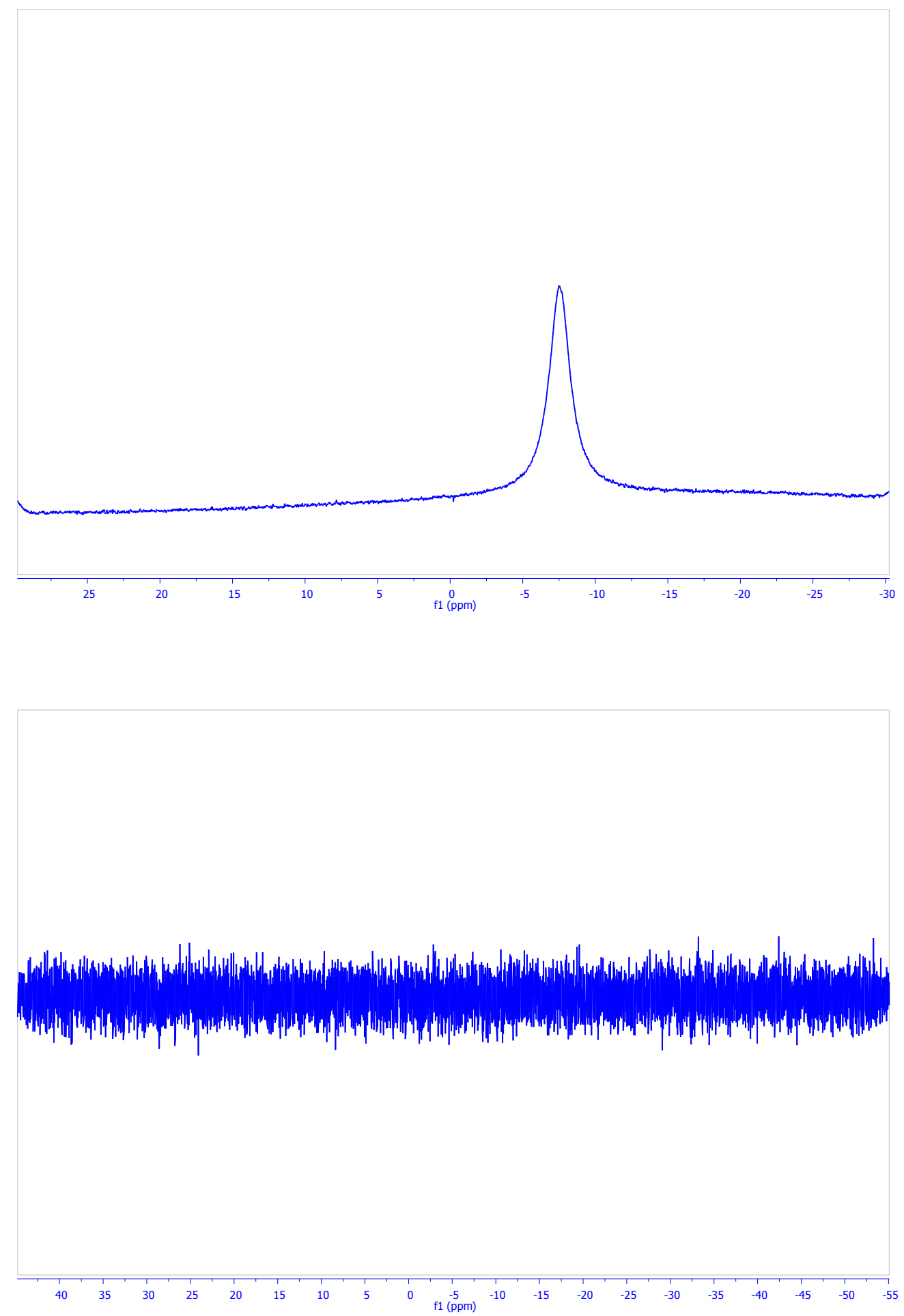

Figure S10. Representative ${ }^{23} \mathrm{Na}$ (top) and ${ }^{7} \mathrm{Li}$ (bottom) NMR spectra in $\mathrm{d}_{6}$-acetone for (NOO) in $\mathrm{Na}$ form. 

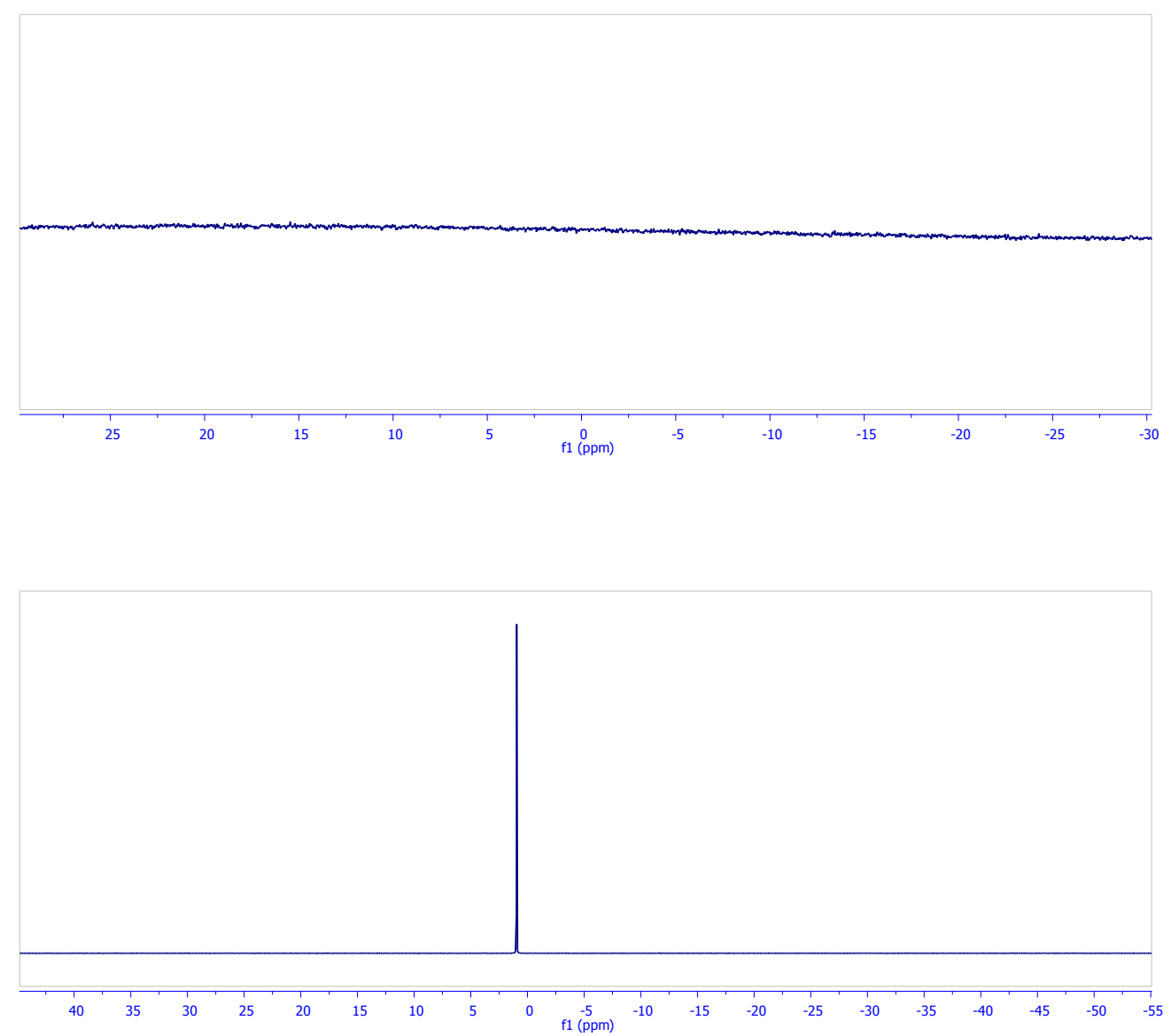

Figure S11. Representative ${ }^{23} \mathrm{Na}$ (top) and ${ }^{7} \mathrm{Li}$ (bottom) NMR spectra in $\mathrm{d}_{6}$-acetone for (NOO) in Li form. 


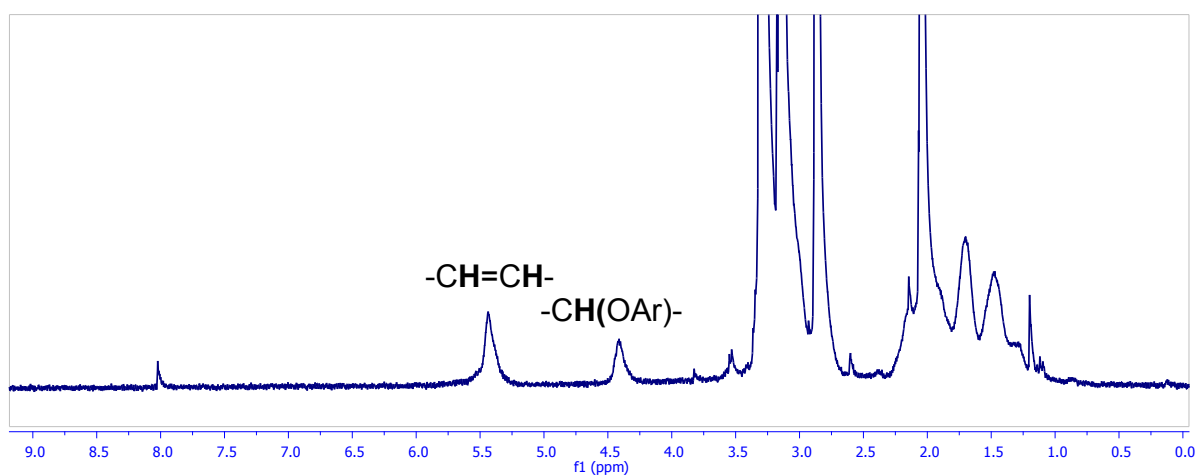

Figure S12. ${ }^{1} \mathrm{H}$ NMR spectrum for the ROMP mixture of A-ON monomer in $\mathrm{d}_{6}$-acetone.

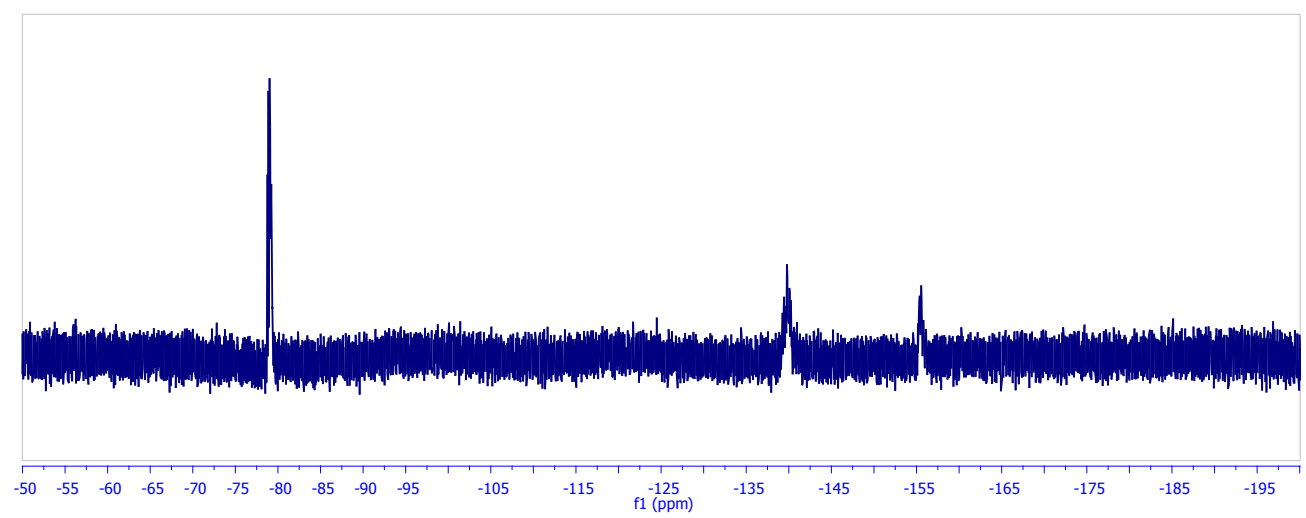

Figure S13. ${ }^{19} \mathrm{~F}$ NMR spectrum for the ROMP mixture of A-ON monomer in $\mathrm{d}_{6}$-acetone.

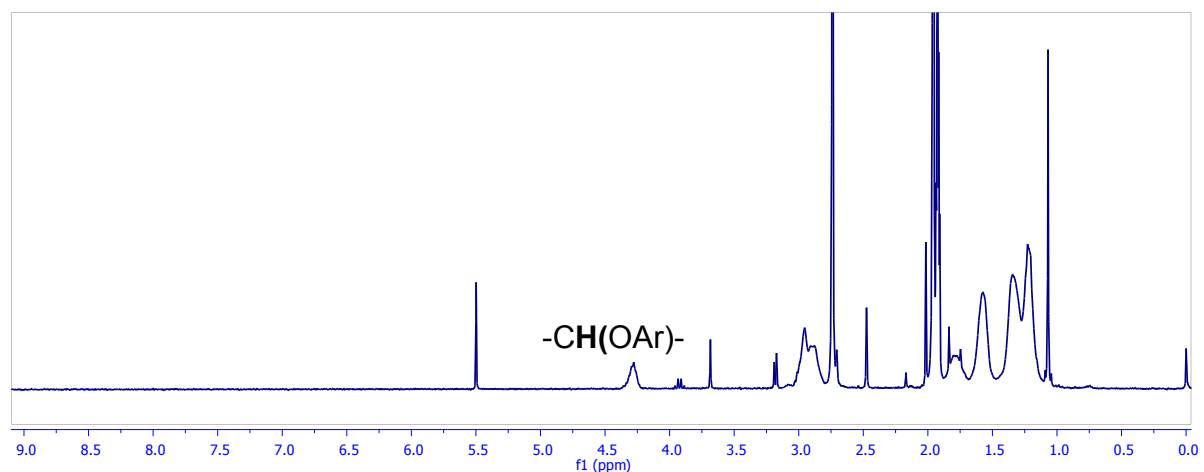

Figure S14. ${ }^{1} \mathrm{H}$ NMR spectrum for $(\mathbf{O N})$ in $\mathrm{d}_{6}$-acetone. 


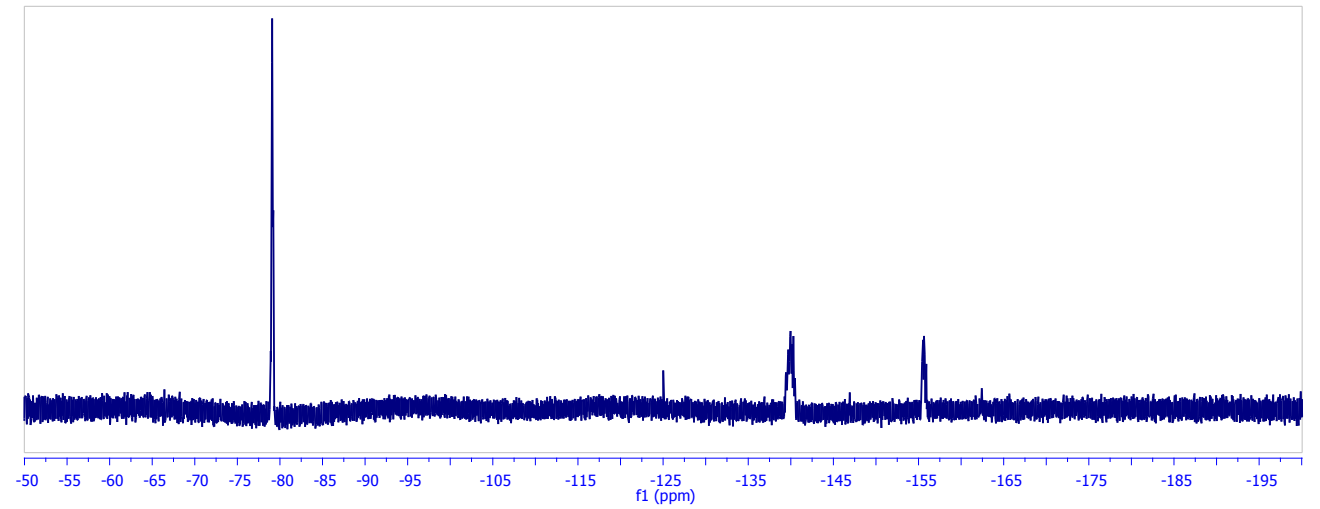

Figure S15. ${ }^{19} \mathrm{~F}$ NMR spectrum for $(\mathbf{O N})$ in $\mathrm{d}_{6}$-acetone.

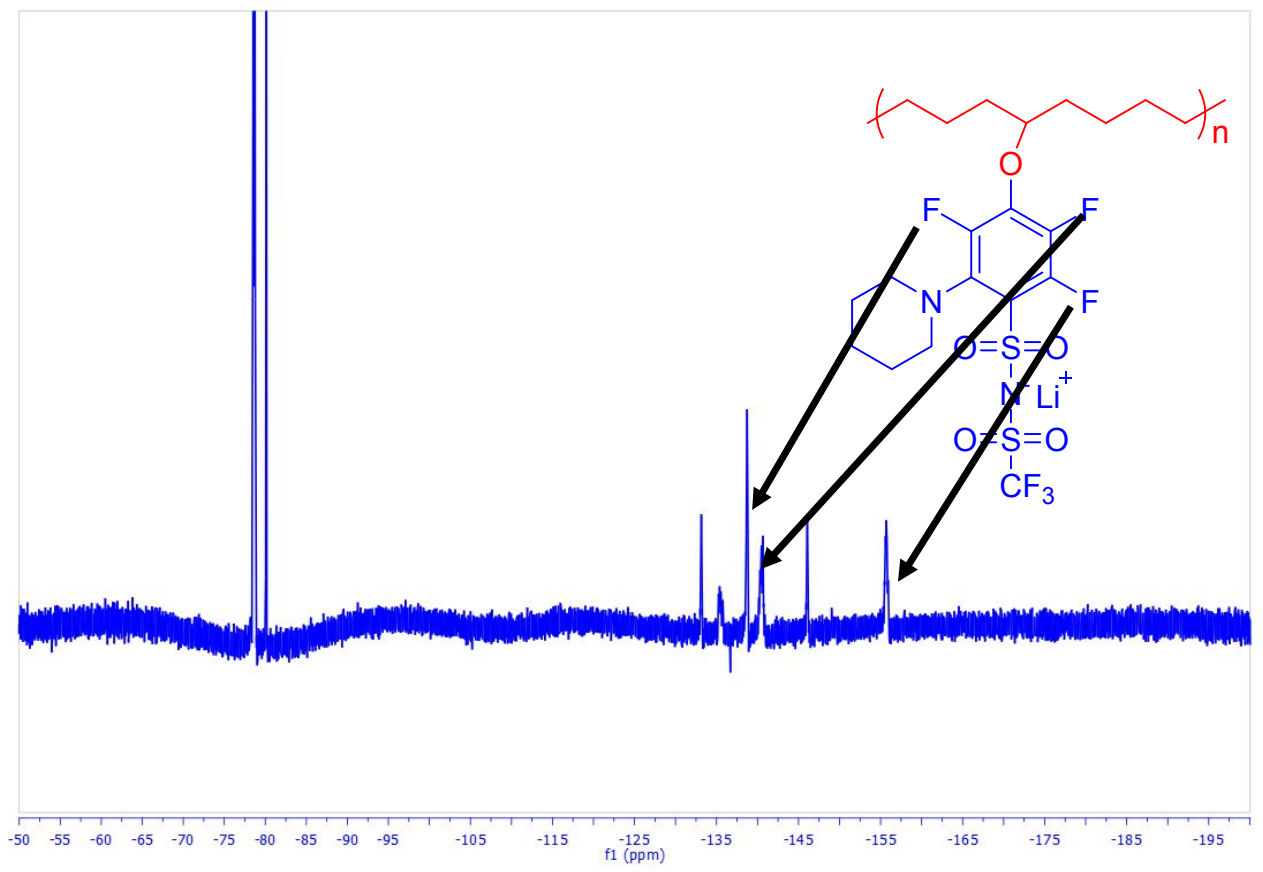

Figure S16. ${ }^{19} \mathrm{~F}$ NMR for $(\mathbf{O N})$ after dialysis in $\mathrm{d}_{6}$-acetone, showing partial protonation. 


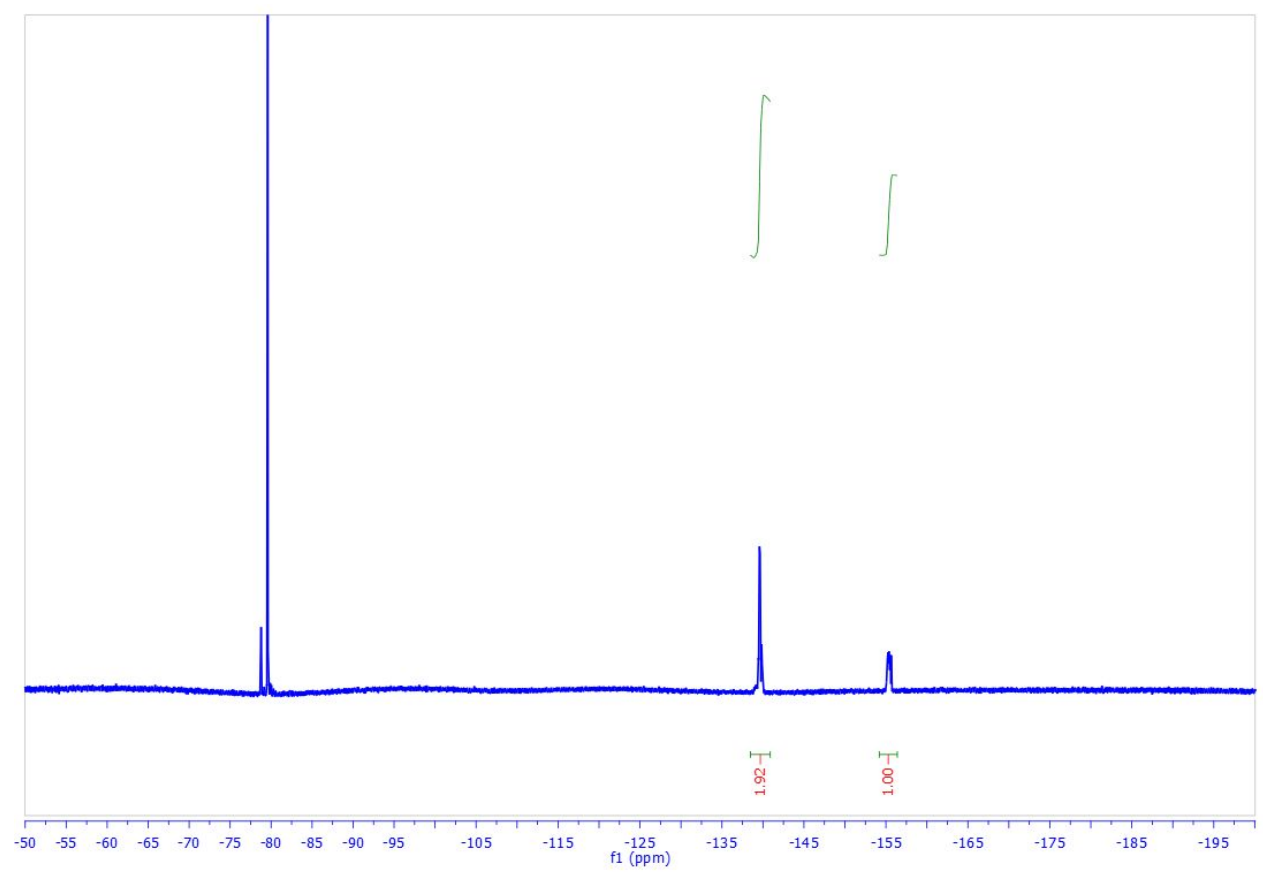

Figure S17. ${ }^{19} \mathrm{~F}$ NMR spectrum for $(\mathbf{O N})$ after full deprotonation in $\mathrm{d}_{4}$-methanol. It was observed that when partially protonated, the polymer can only be suspended in water (cloudy and opaque), while the deprotonated polymer can be easily dissolved in organic solvent.

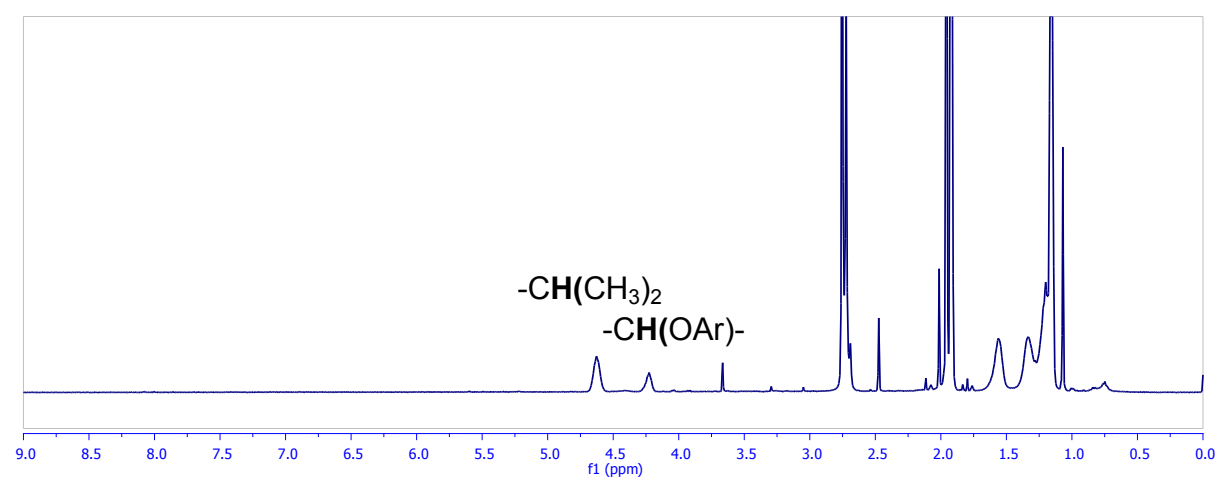

Figure S18. ${ }^{1} \mathrm{H}$ NMR spectrum for (OOO) in $\mathrm{d}_{6}$-acetone. 


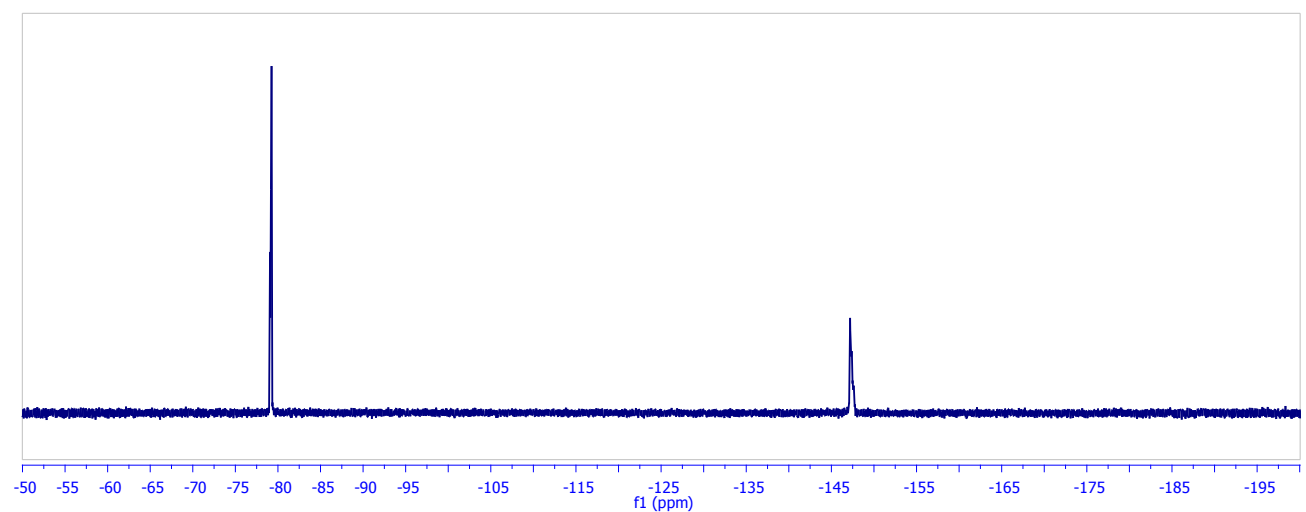

Figure S19. ${ }^{19} \mathrm{~F}$ NMR spectrum of (OOO) in $\mathrm{d}_{6}$-acetone.

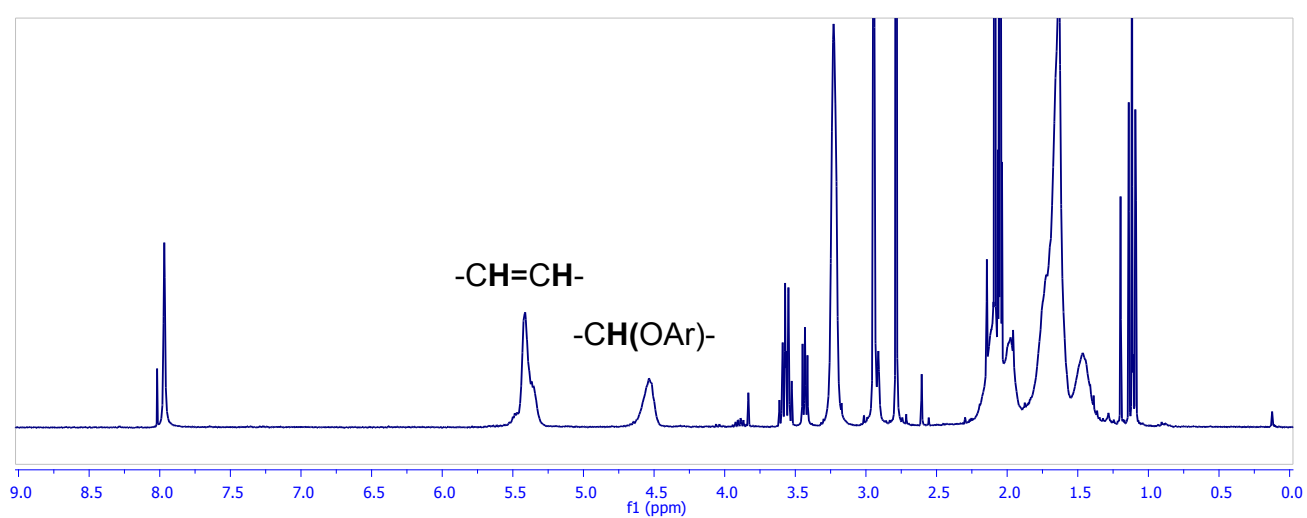

Figure S20. ${ }^{1} \mathrm{H}$ NMR spectrum for ROMP mixture of A-NO monomer in $\mathrm{d}_{6}$-acetone.

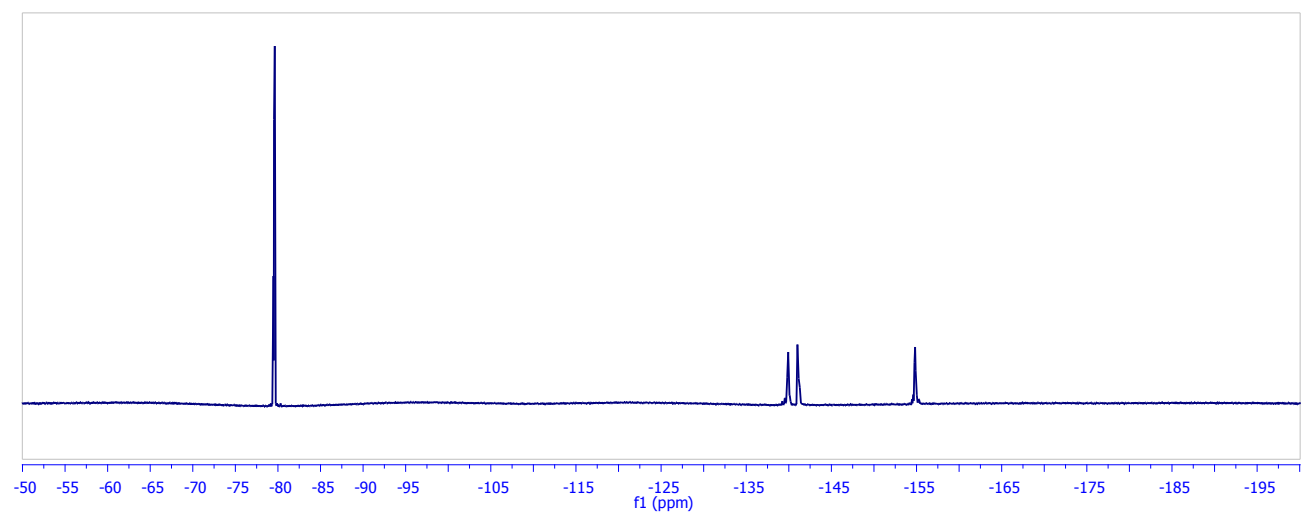

Figure S21. ${ }^{19} \mathrm{~F}$ NMR spectrum for ROMP mixture of A-NO monomer in $\mathrm{d}_{6}$-acetone. 


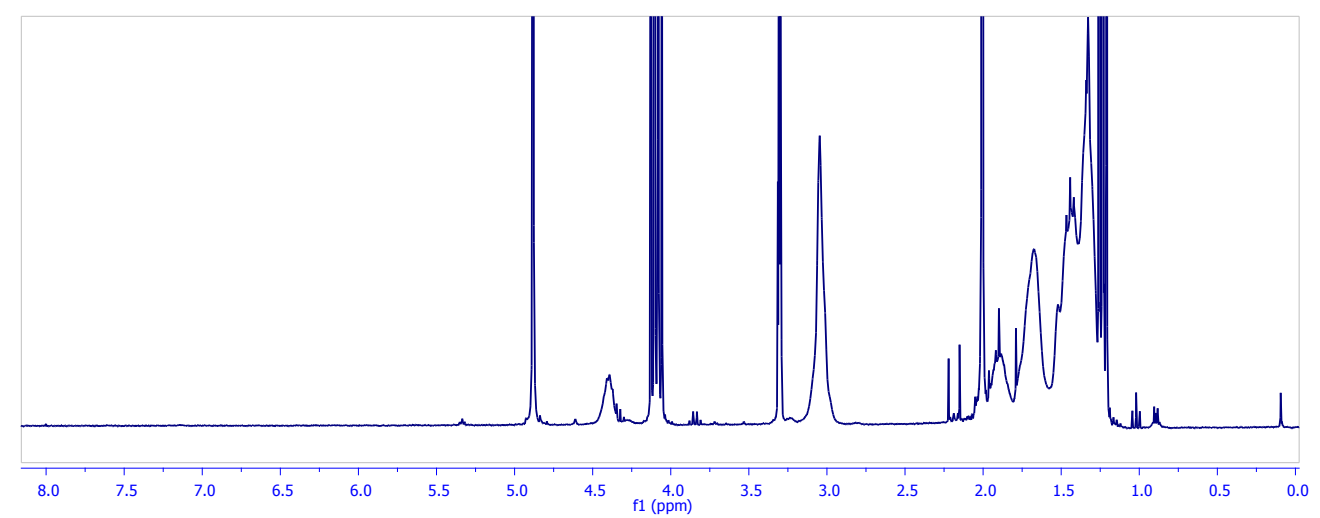

Figure S22. ${ }^{1} \mathrm{H}$ NMR spectrum for (NO) in $\mathrm{d}_{4}$-methanol, with ethyl acetate.

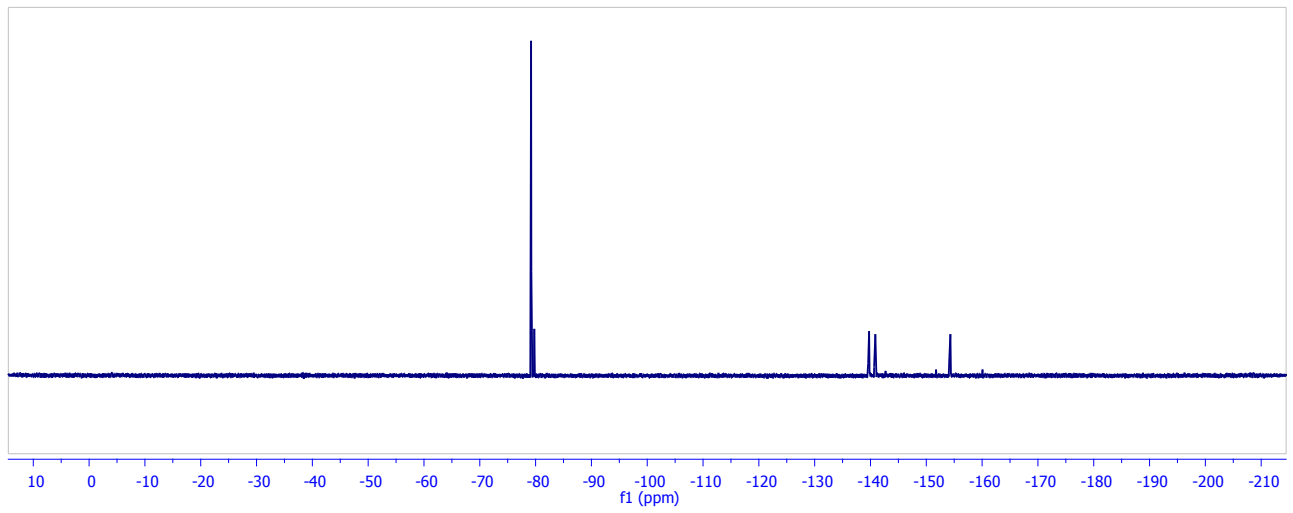

Figure S23. ${ }^{19} \mathrm{~F}$ NMR spectrum for (NO) in $\mathrm{d}_{4}$-methanol.

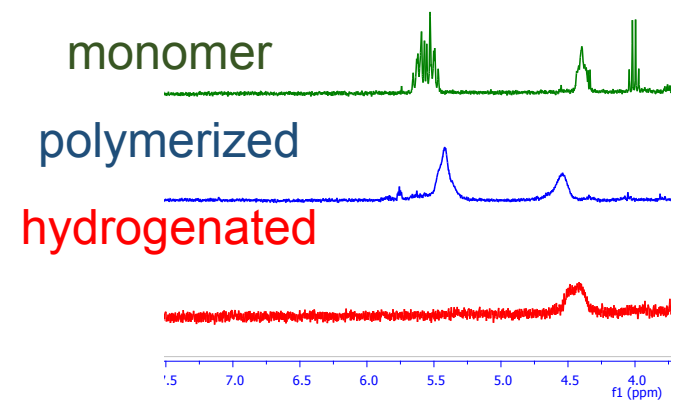

Figure S24. Representative ${ }^{1} \mathrm{H}$ NMR spectra comparing the monomer (in $\mathrm{d}_{6}$-dimethylsulfoxide), polymerization mixture (in $\mathrm{d}_{6}$-acetone), and hydrogenation product, (NO) (in $\mathrm{d}_{6}$-acetone). 


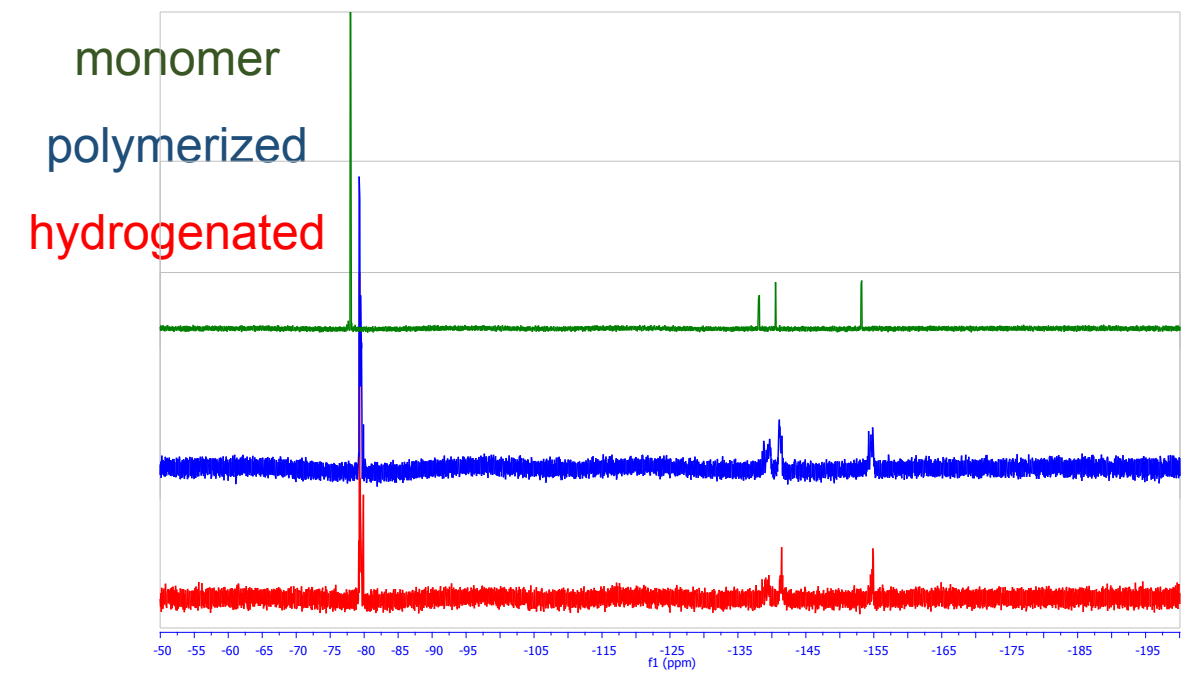

Figure S25. Representative ${ }^{19} \mathrm{~F}$ NMR spectra comparing the monomer (in $\mathrm{d}_{6}$-dimethylsulfoxide), polymerization mixture (in $\mathrm{d}_{6}$-acetone), and hydrogenation product, (NO) (in $\mathrm{d}_{6}$-acetone).

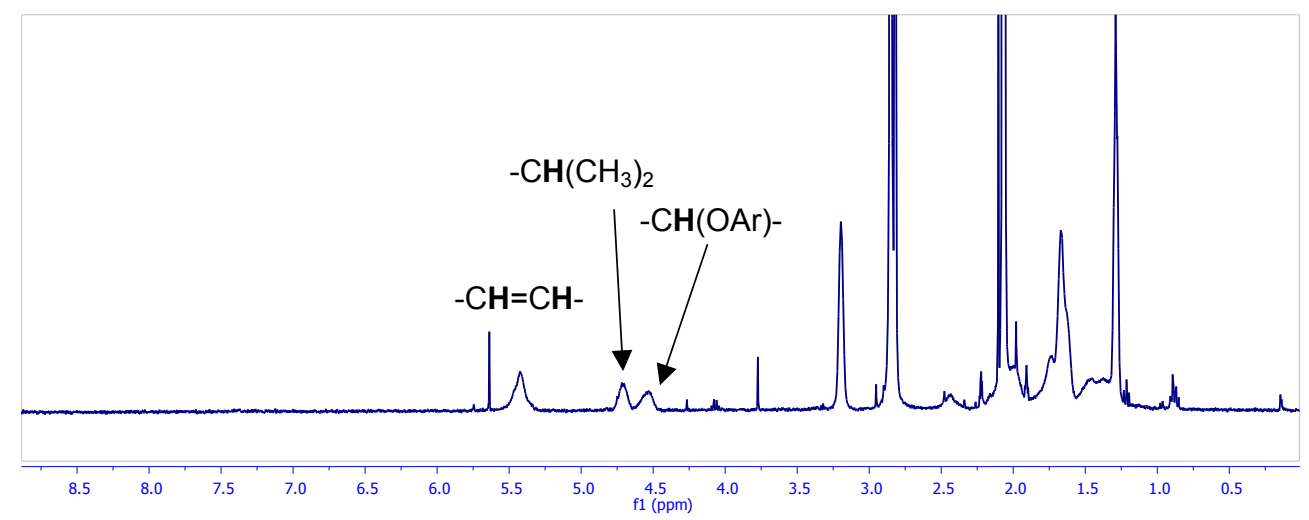

Figure S26. ${ }^{1} \mathrm{H}$ NMR spectrum for ROMP mixture of A-NOO monomer in $\mathrm{d}_{6}$-acetone.

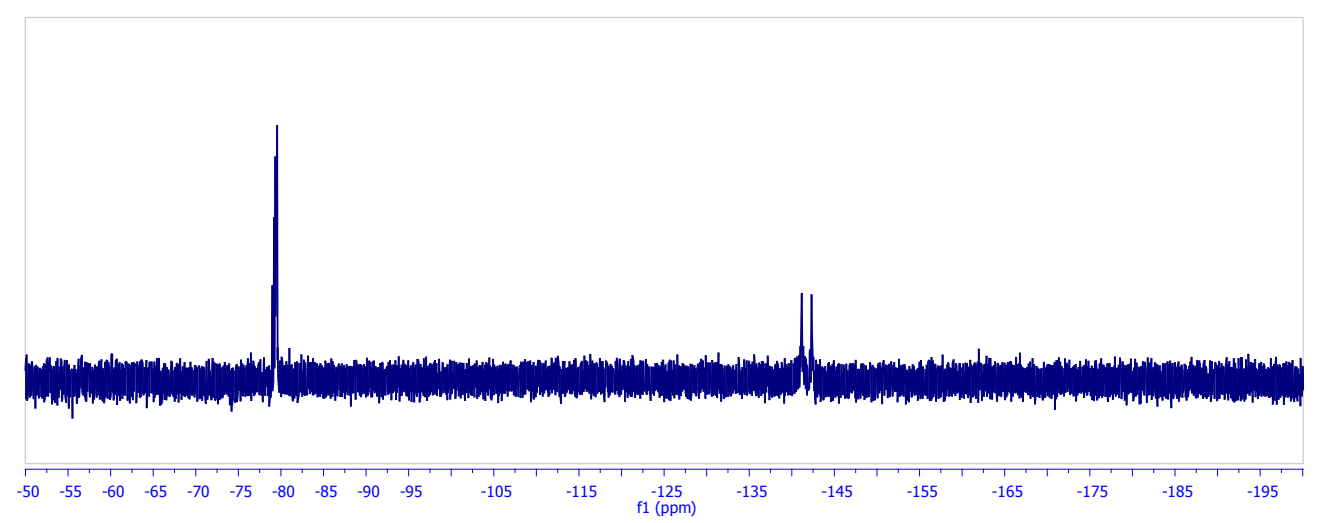

Figure S27. ${ }^{19} \mathrm{~F}$ NMR spectrum for ROMP mixture of A-NOO monomer in $\mathrm{d}_{6}$-acetone. 


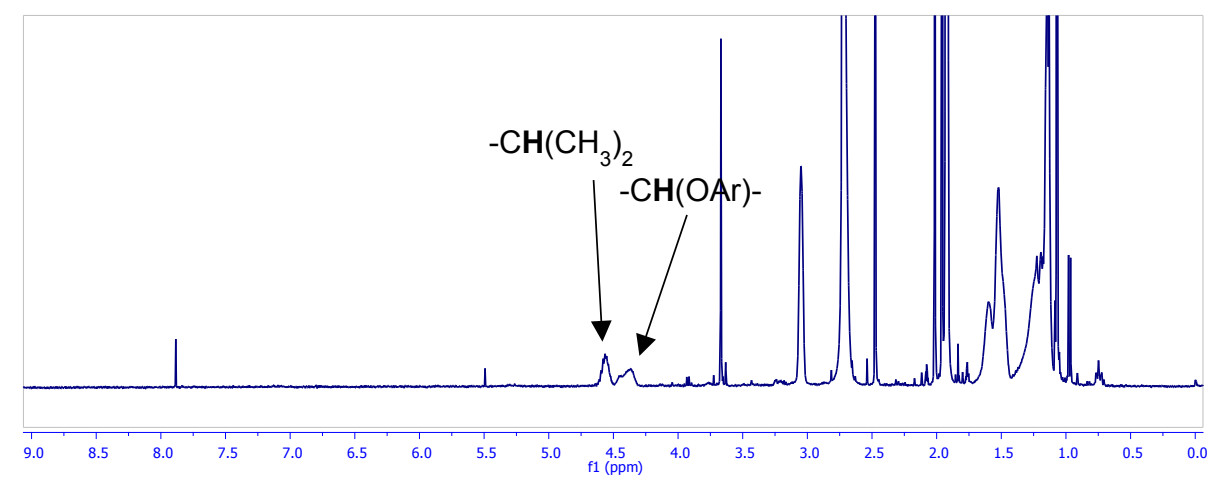

Figure S28. ${ }^{1} \mathrm{H}$ NMR spectrum for (NOO) in $\mathrm{d}_{6}$-acetone.

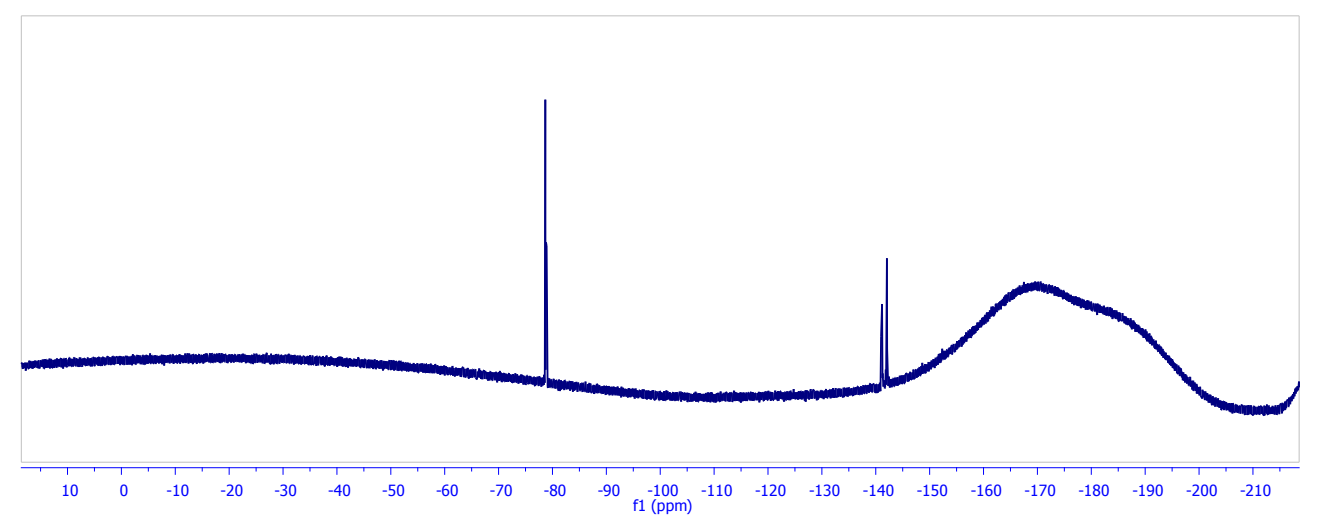

Figure S29. ${ }^{19} \mathrm{~F}$ NMR spectrum for (NOO) in $\mathrm{d}_{6}$-acetone.

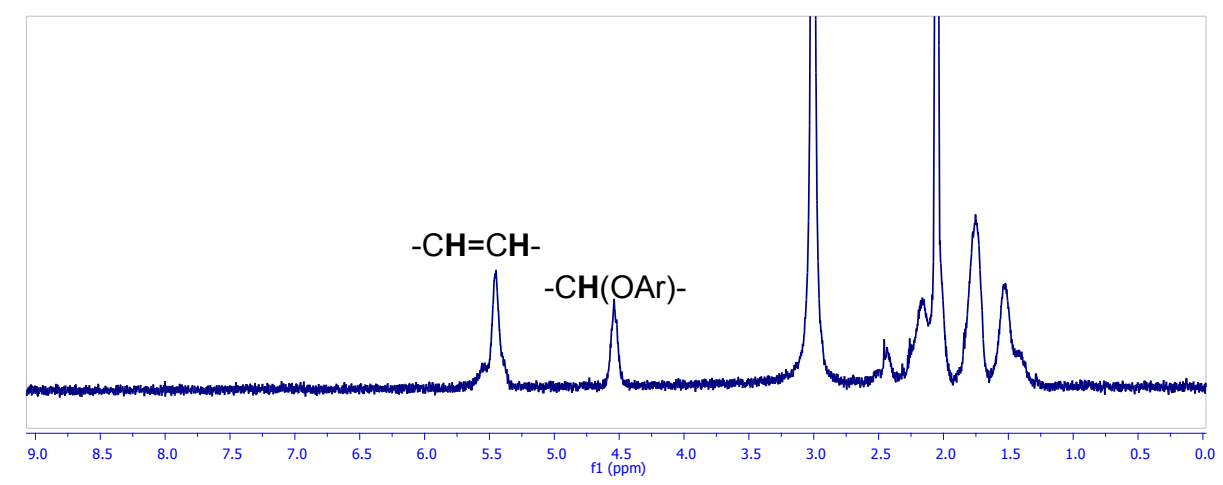

Figure S30. ${ }^{1} \mathrm{H}$ NMR spectrum for ROMP mixture of A-O monomer in $\mathrm{d}_{3}$-acetonitrile. 


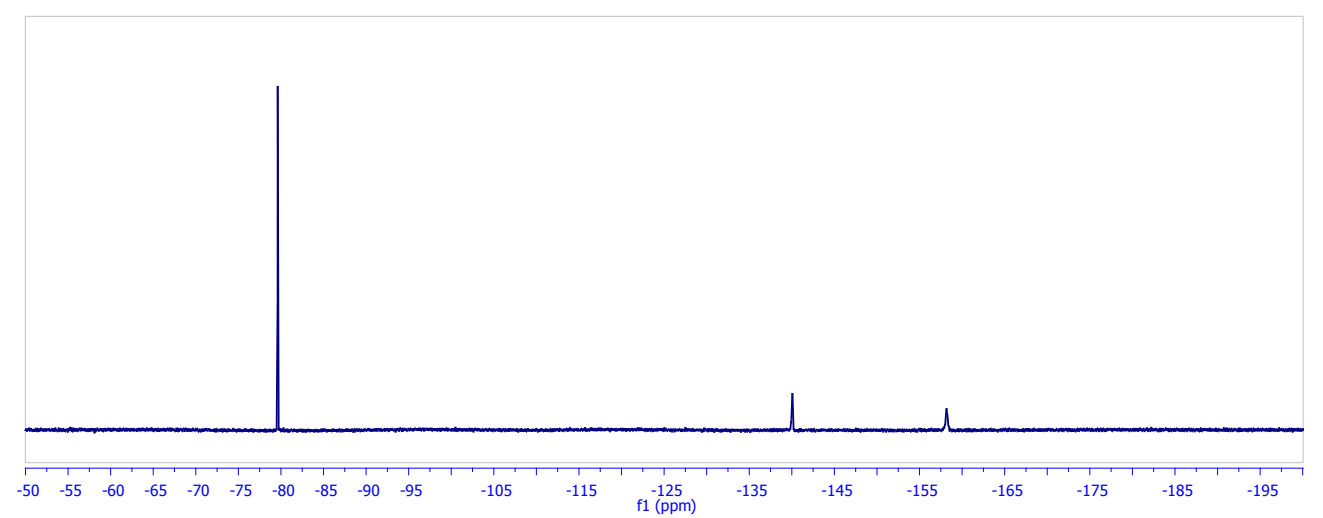

Figure S31. ${ }^{19} \mathrm{~F}$ NMR spectrum for ROMP mixture of A-O monomer in $\mathrm{d}_{3}$-acetonitrile.

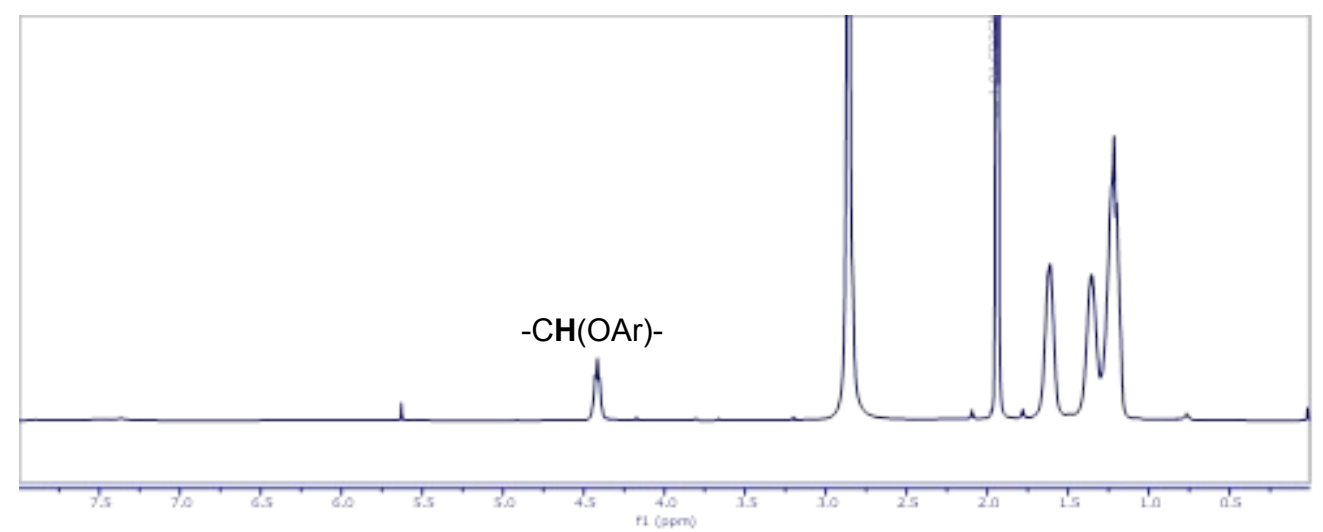

Figure S32. ${ }^{1} \mathrm{H}$ NMR spectrum for $(\mathbf{O})$ in $\mathrm{d}_{6}$-acetone.

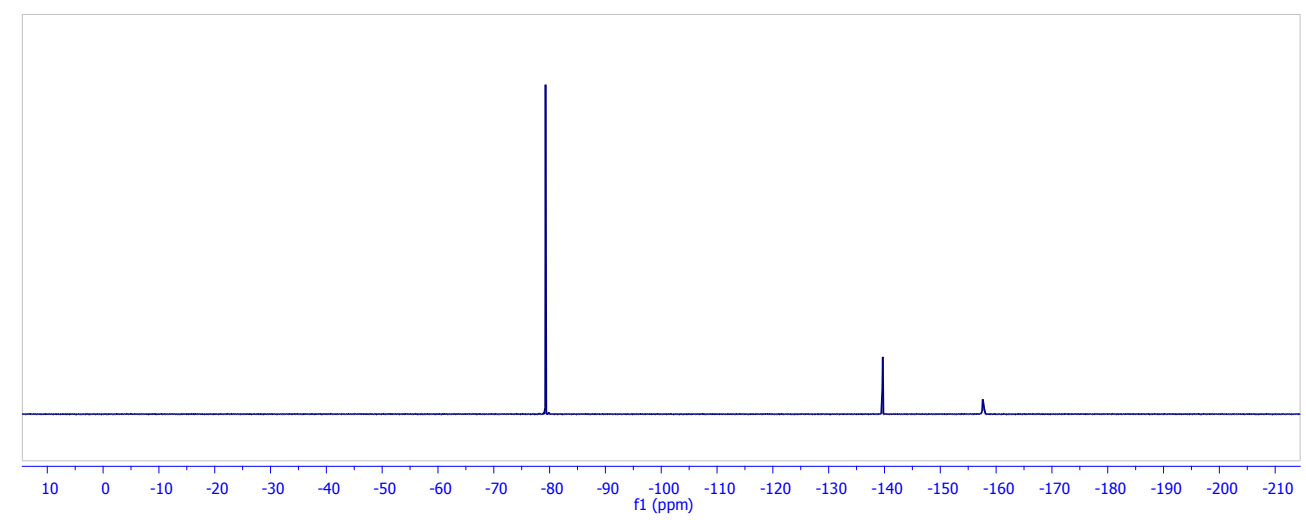

Figure S33. ${ }^{19} \mathrm{~F}$ NMR spectrum for $(\mathbf{O})$ in $\mathrm{d}_{6}$-acetone. 

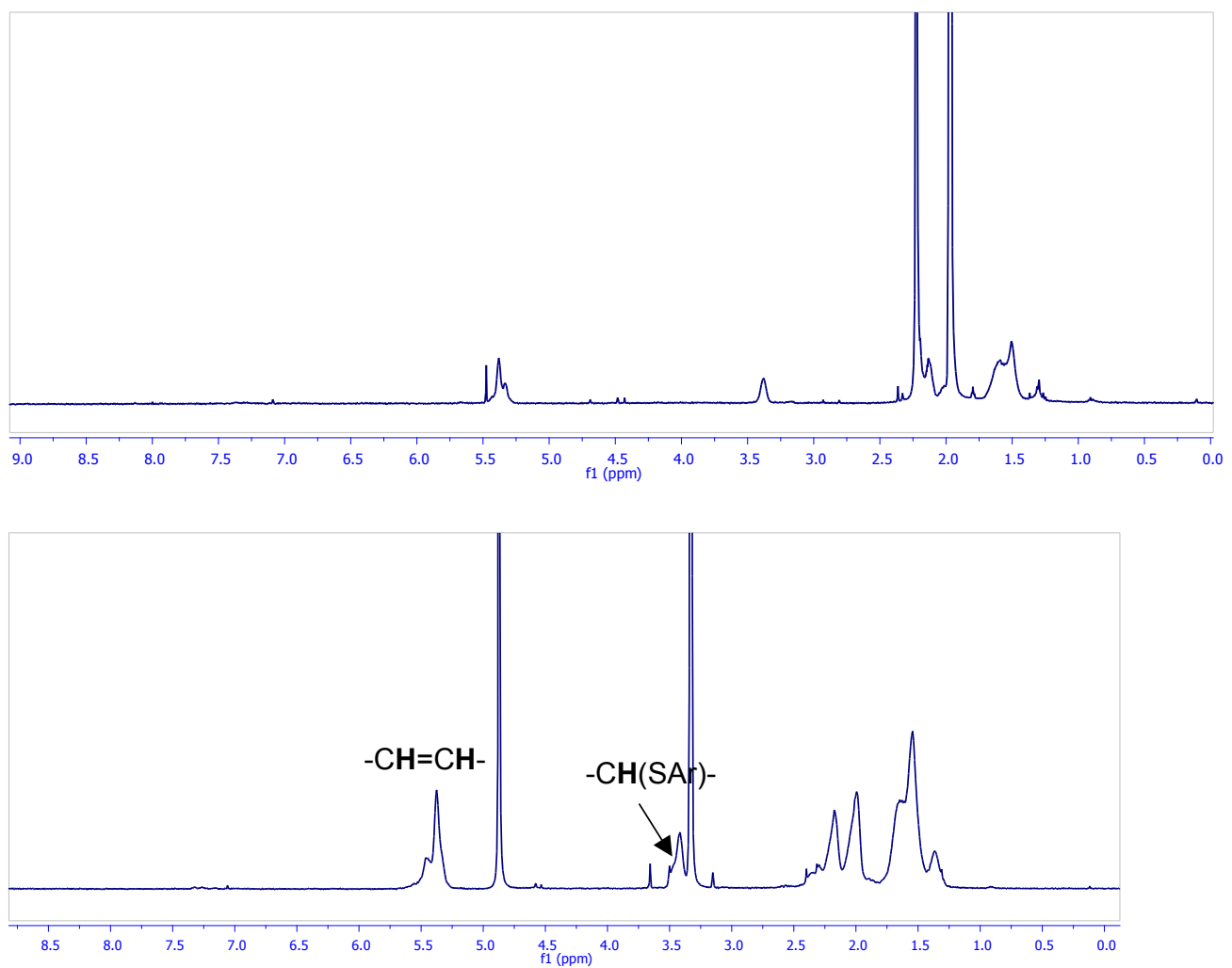

Figure S34. ${ }^{1} \mathrm{H}$ NMR spectra for (S)' in $\mathrm{d}_{3}$-acetonitrile (top) and $\mathrm{d}_{4}$-methanol (bottom).

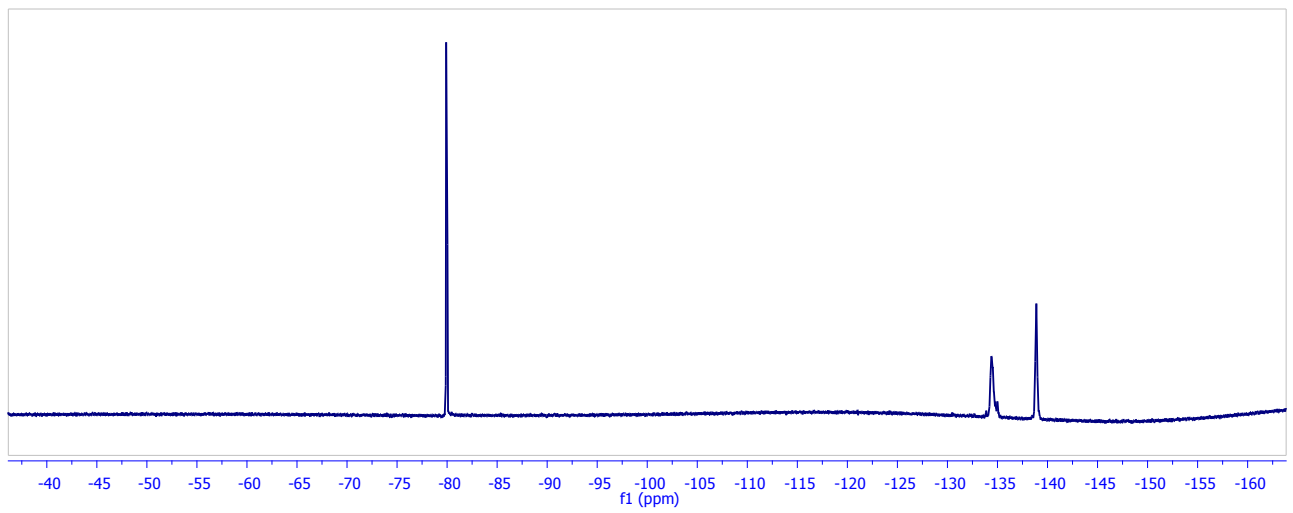

Figure S35. ${ }^{19} \mathrm{~F}$ NMR spectrum for (S)' in $\mathrm{d}_{4}$-methanol. 


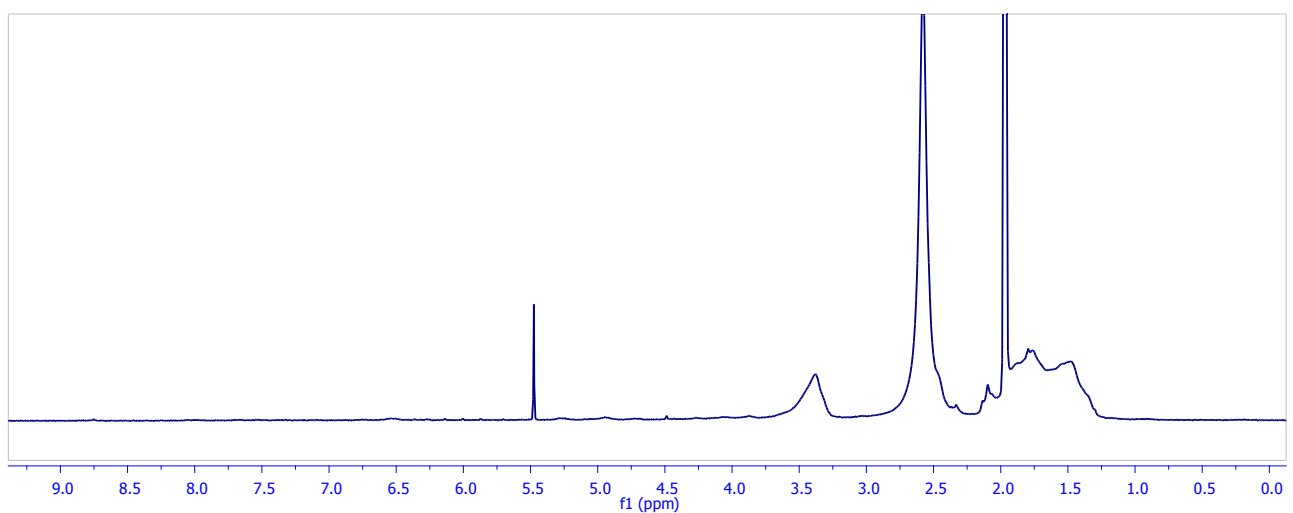

Figure S36. ${ }^{1} \mathrm{H}$ NMR spectrum for (Sox)'" in $\mathrm{d}_{3}$-acetonitrile.

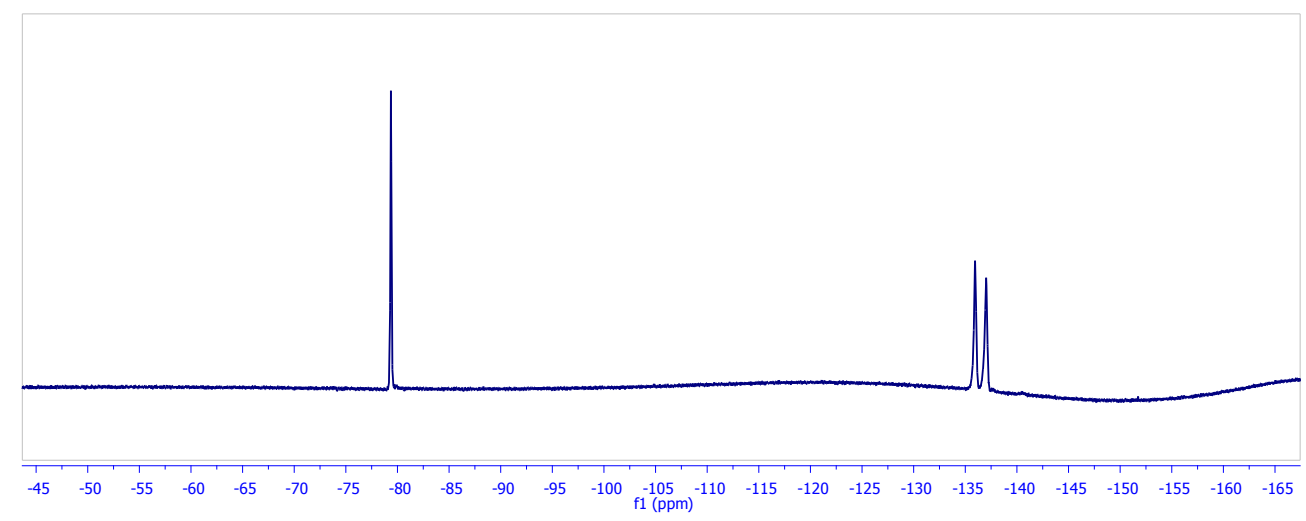

Figure S37. ${ }^{19}$ F NMR spectrum for (Sox)'” $\mathrm{d}_{3}$-acetonitrile. 


\section{S6. Gel permeation chromatography and diffusion-ordered spectroscopy}

We attempted to use gel permeation chromatography (GPC) for the analysis of MW. A typical procedure is as following. GPC-MALLS characterization was performed on an Agilent 1260 LC system equipped with a Wyatt T-rEX refractive index (dRI) detector and Wyatt DAWN HELEOS 18 angle light scattering detector. Samples were run on two Agilent PLgel $5 \mu \mathrm{m}$ MIXED-C GPC columns in series at a temperature of $60 \mathrm{oC}$ and flow rate of $1 \mathrm{~mL} / \mathrm{min}$ with dimethyl formamide (DMF) containing $0.025 \mathrm{M} \mathrm{LiBr}$ as the eluent. However, no signal can be detected for any of the samples. Similarly, using THF and water (phosphate-buffered saline) did not provide any detectable signal.

Thus, we used Diffusion Ordered Spectroscopy (DOSY) NMR for the understanding of the MW of these samples. DOSY spectra were recorded on a Bruker AVANCE-500 MHz NMR spectrometer and analyzed on MestReNova NMR software. Chemical shifts are expressed in parts per million (ppm).

DOSY NMR ( ${ }^{19} \mathrm{~F}$ signal) was used along with the Stokes-Einstein equation to estimate that the hydrodynamic diameters of the polymer samples are $\sim 5$-fold larger than LiTFSI, supporting their polymeric nature.

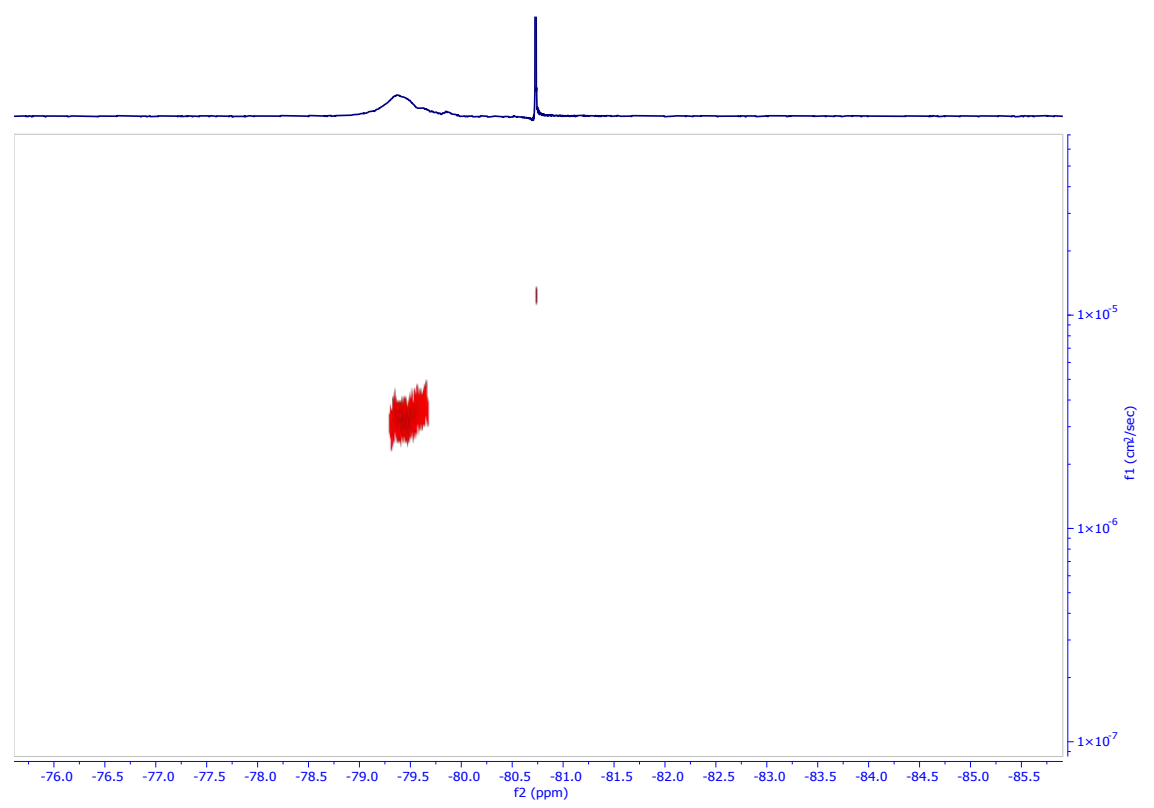

Figure S38. DOSY NMR spectrum $\left({ }^{19} \mathrm{~F}\right.$ signal at $\left.\mathbf{C F}_{3^{-}}\right)$for PHS and LiTFSI in $\mathrm{d}_{4}$-methanol. 


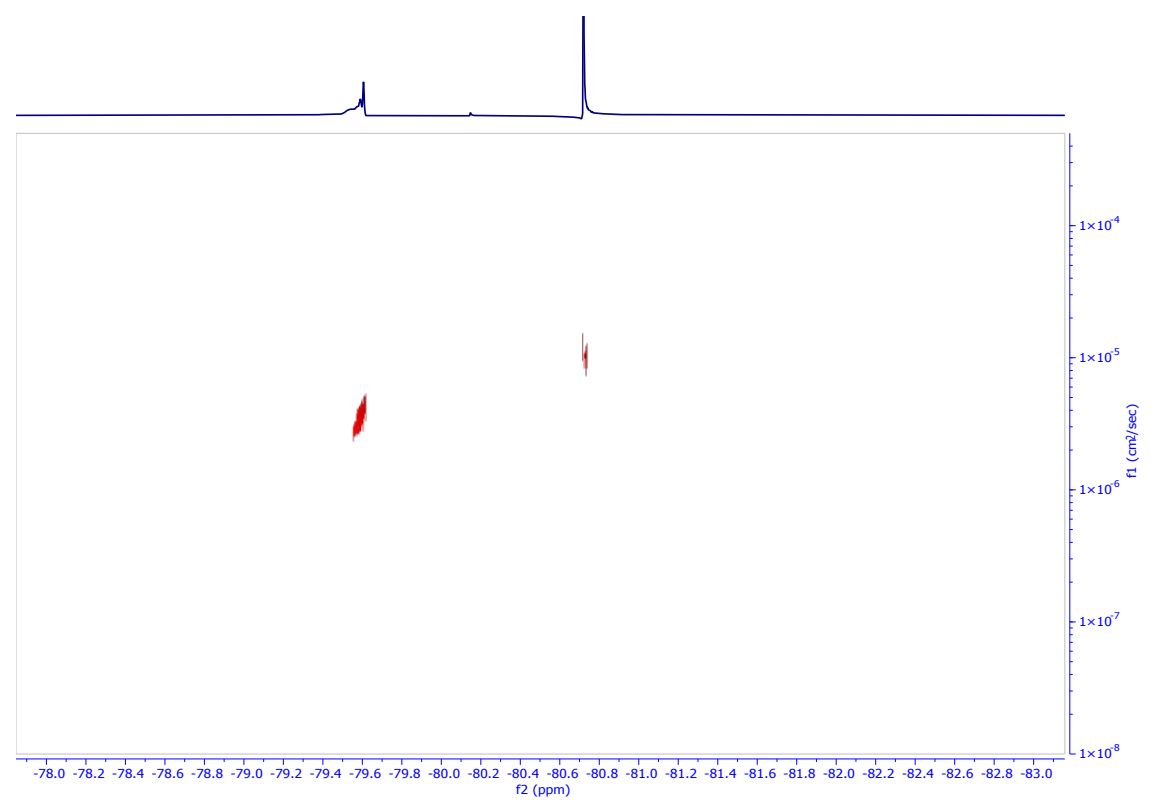

Figure S39. DOSY NMR spectrum $\left({ }^{19} \mathrm{~F}\right.$ signal at $\left.\mathrm{CF}_{3^{-}}\right)$for $(\mathbf{N O})$ and LiTFSI in $\mathrm{d}_{4}$-methanol.

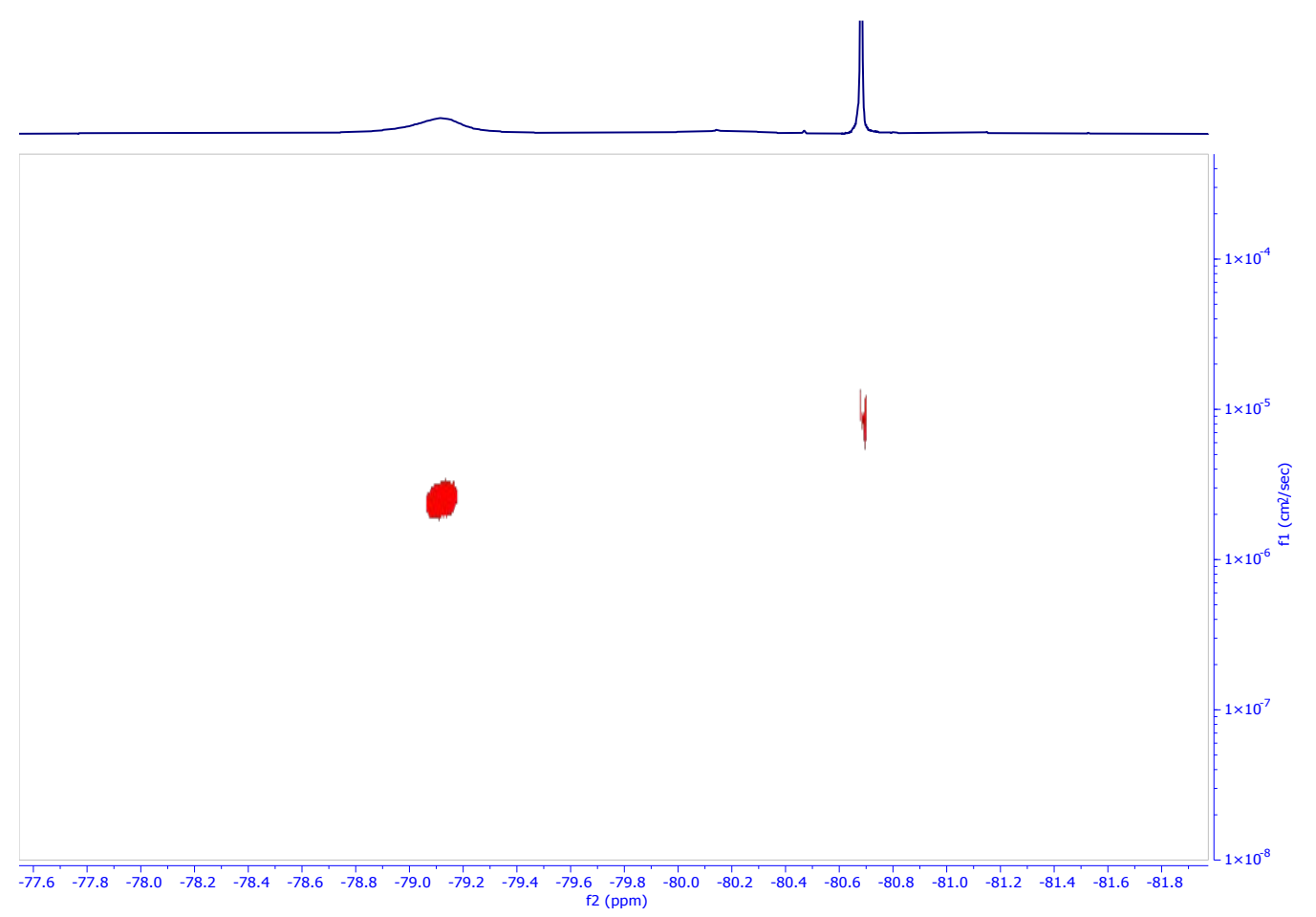

Figure S40. DOSY NMR spectrum $\left({ }^{19} \mathrm{~F}\right.$ signal at $\left.\mathrm{CF}_{3^{-}}\right)$for $(\mathbf{O N})$ and LiTFSI in $\mathrm{d}_{4}$-methanol. 


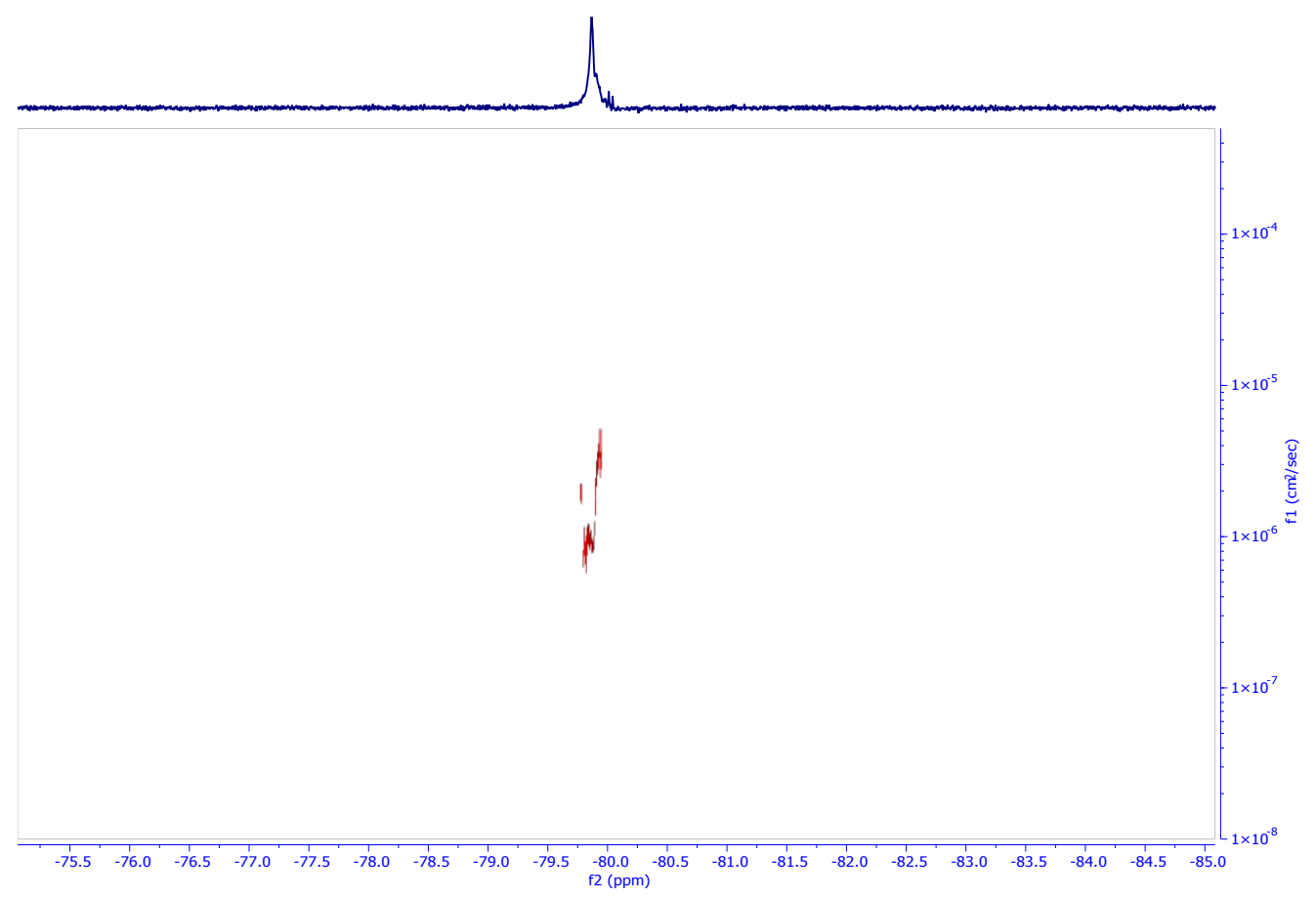

Figure S41. DOSY NMR spectrum $\left({ }^{19} \mathrm{~F}\right.$ signal at $\left.\mathrm{CF}_{3^{-}}\right)$for $(\mathbf{S})$ ' in $\mathrm{d}_{4}$-methanol.

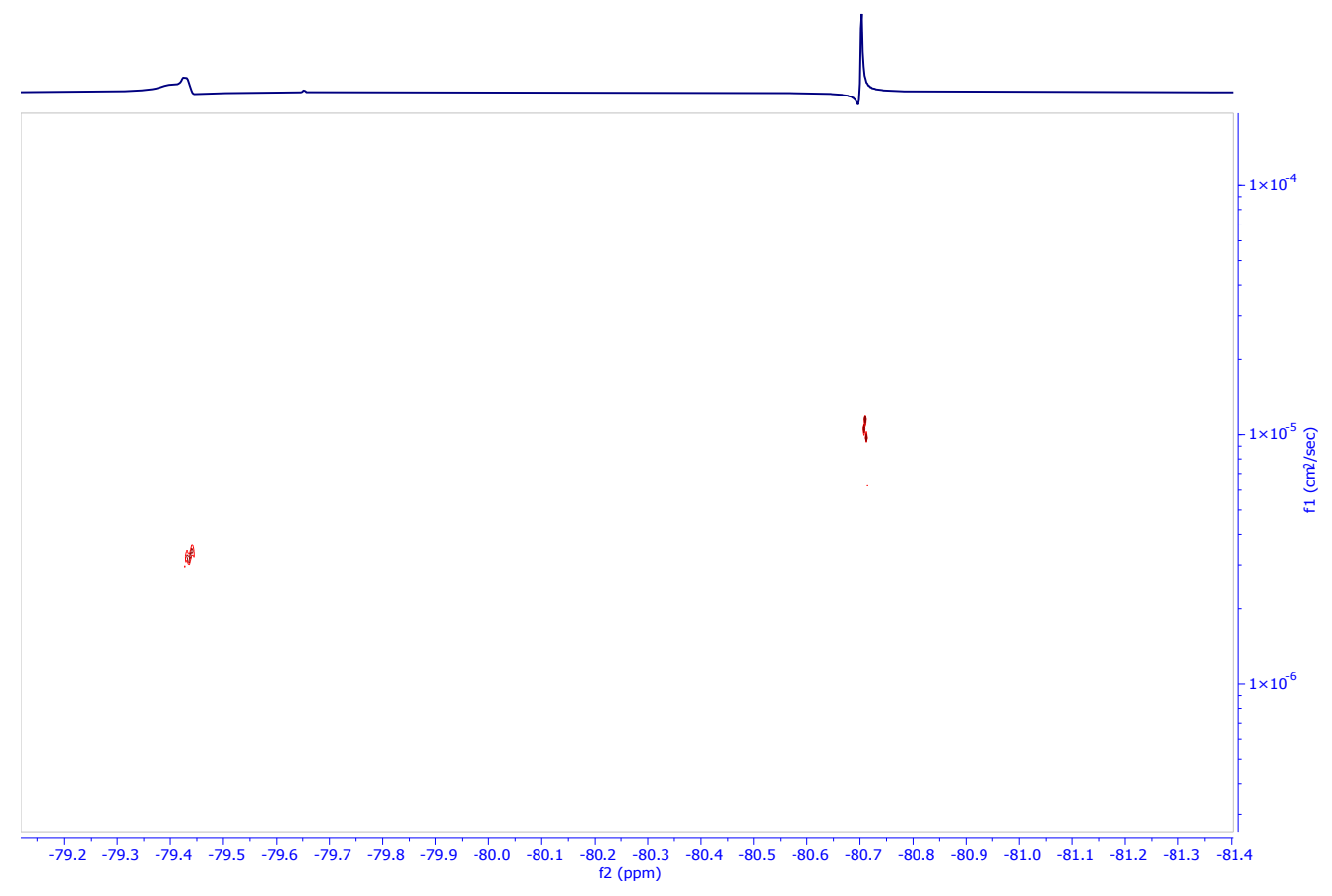

Figure $\mathbf{S 4 2}$. DOSY NMR spectrum $\left({ }^{19} \mathrm{~F}\right.$ signal at $\left.\mathrm{CF}_{3^{-}}\right)$for $(\mathbf{N O O})$ and LiTFSI in $\mathrm{d}_{4}$-methanol. 


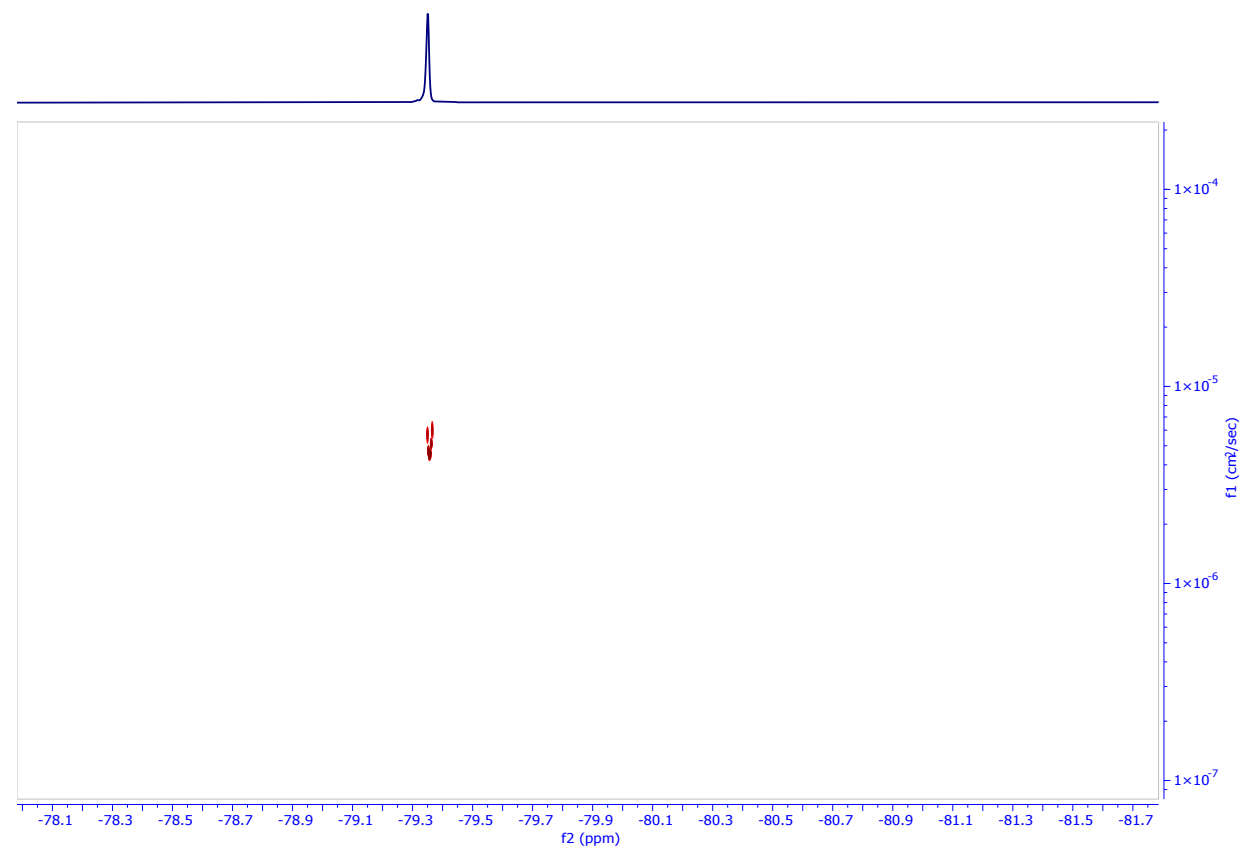

Figure S43. DOSY NMR spectrum $\left({ }^{19} \mathrm{~F}\right.$ signal at $\left.\mathrm{CF}_{3^{-}}\right)$for $(\mathbf{O})$ in $\mathrm{d}_{4}$-methanol.

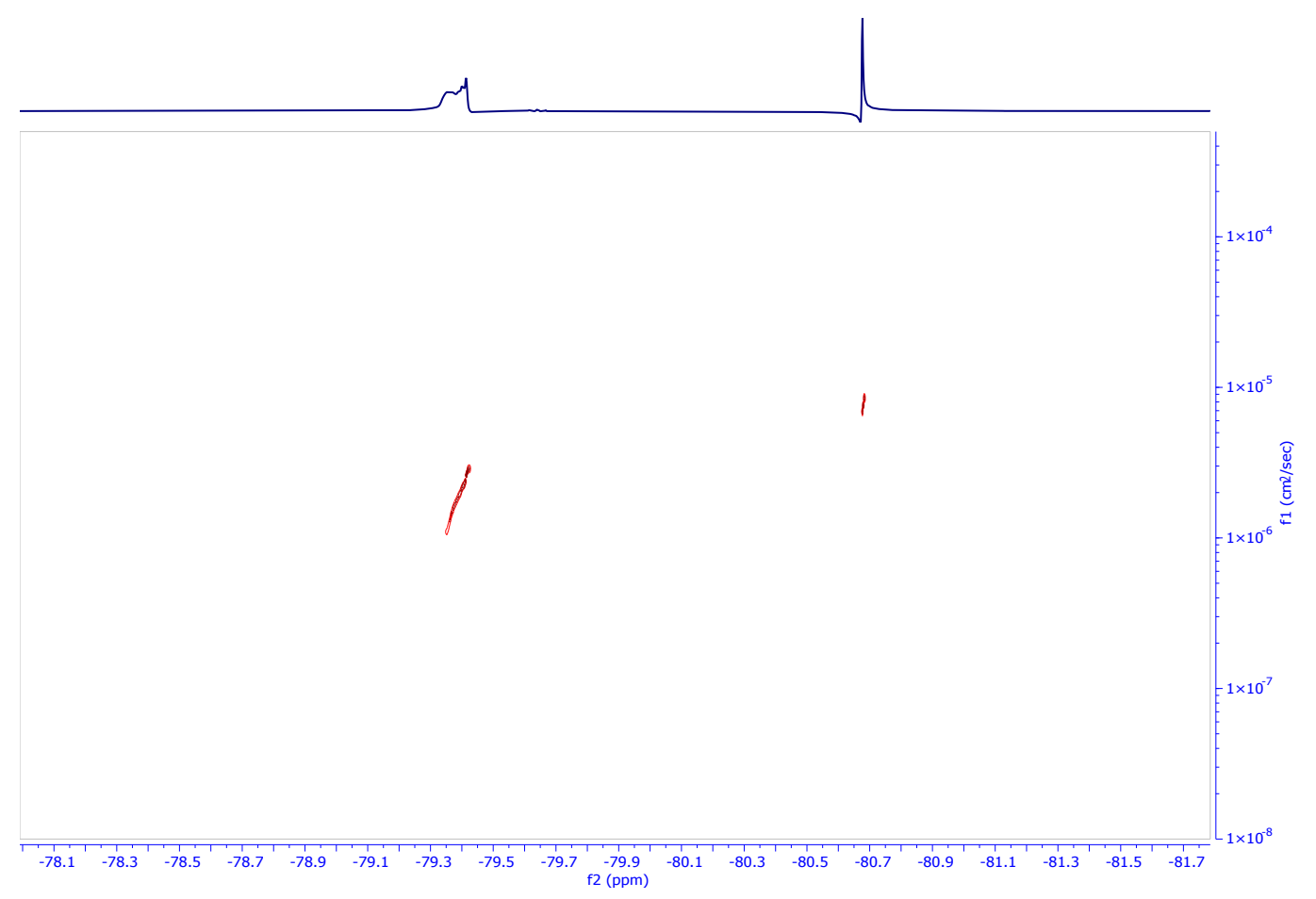

Figure S44. DOSY NMR spectrum $\left({ }^{19} \mathrm{~F}\right.$ signal at $\left.\mathrm{CF}_{3^{-}}\right)$for $(\mathbf{O O O})$ and LiTFSI in $\mathrm{d}_{4}$-methanol. 


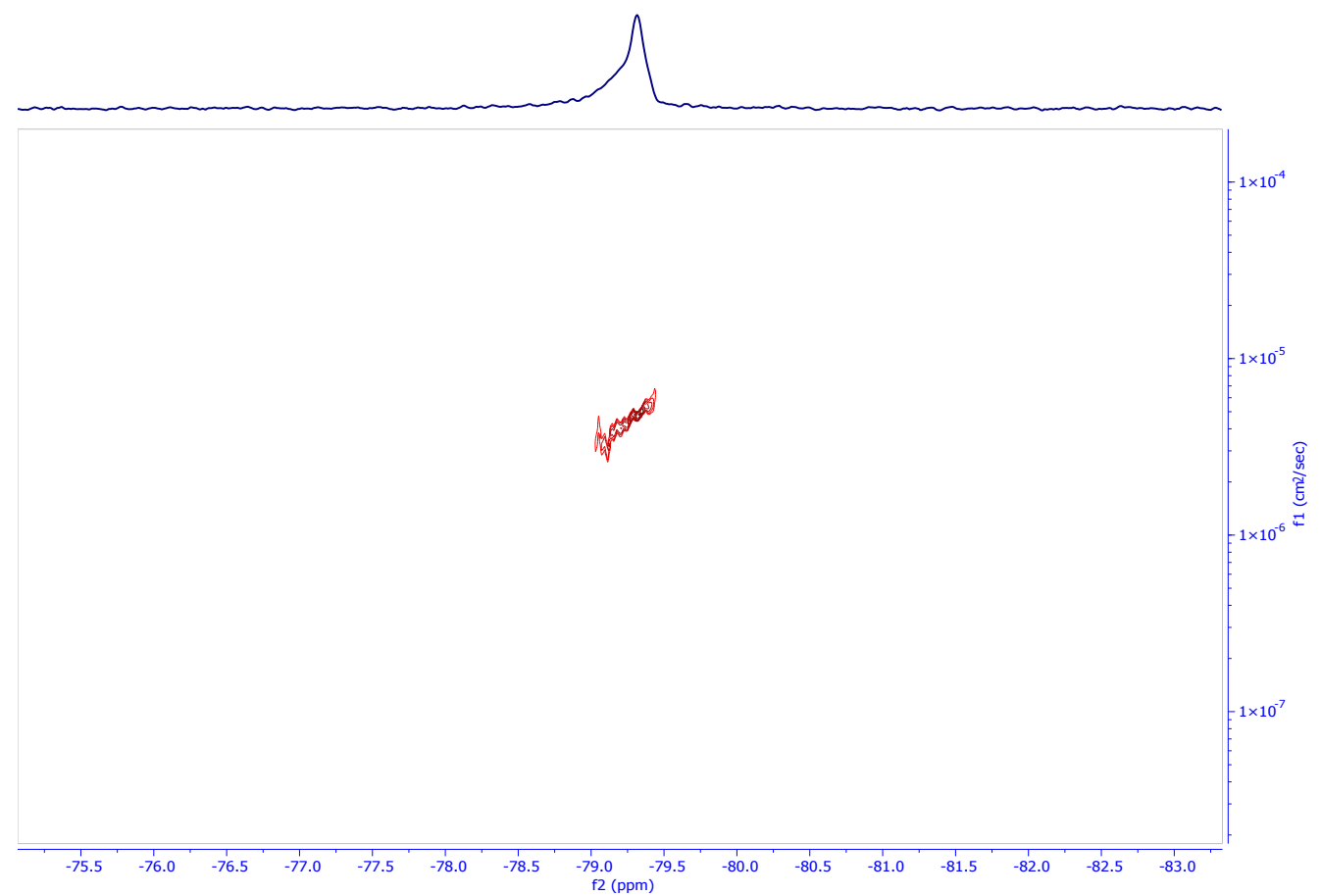

Figure S45. DOSY NMR spectrum ( ${ }^{19} \mathrm{~F}$ signal at $\left.\mathrm{CF}_{3^{-}}\right)$for (Sox)' ${ }^{\prime}$ in $\mathrm{d}_{4}$-methanol. 


\section{S7. Thermal Analysis and X-ray Scattering}

Differential scanning calorimetry (DSC) characterization was conducted using a TA Q1000 instrument under dry $\mathrm{N}_{2}$ flow. The sealed samples were heated from room temperature to $100{ }^{\circ} \mathrm{C}$ at $10{ }^{\circ} \mathrm{C} / \mathrm{min}$ to remove thermal history. Then, they were cooled to $-70{ }^{\circ} \mathrm{C}$ before being ramped to $100^{\circ} \mathrm{C}$ again $\left(10^{\circ} \mathrm{C} / \mathrm{min}\right)$. The melting peaks in the second heating cycle were analyzed using a PEO melting enthalpy value of 206 $\mathrm{J} / \mathrm{g} .{ }^{9}$ The results are summarized in Table $\mathrm{S} 1$ and a representative curve in Figure S46. It is noted that the glass transition temperatures were not observed clearly.

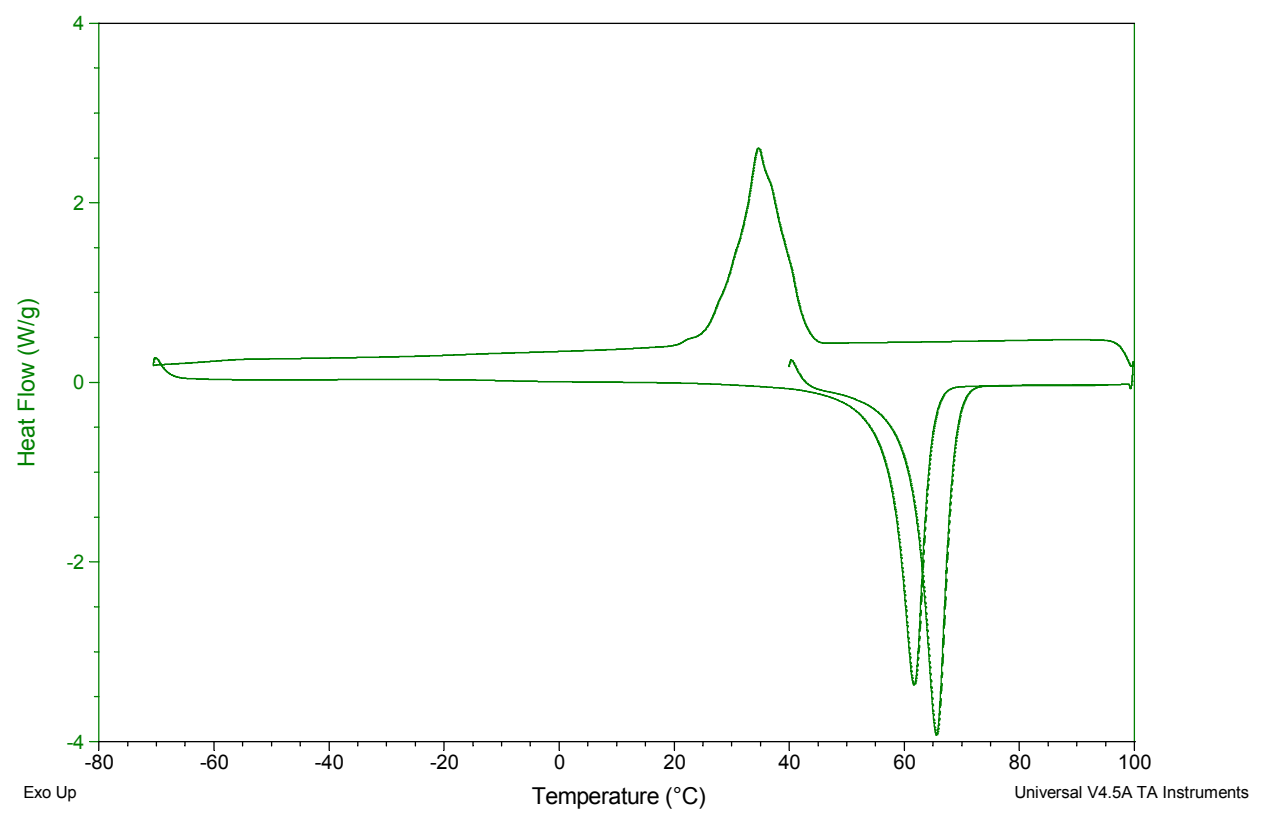

Figure S46. Representative DSC curve of (NO)/PEO $\left([\mathrm{EO}] /\left[\mathrm{Li}^{+}\right]=57\right)$.

Table S1. Summarized DSC analysis results of polyanion/PEO blends.

\begin{tabular}{|c|c|c|c|c|c|}
\hline anion & {$[\mathrm{EO}] /[\mathrm{Li}]$} & $\mathrm{T}_{\mathrm{m}}\left({ }^{\circ} \mathrm{C}\right)$ & $\mathrm{wt} \%$ of $\mathrm{PEO}$ & $\Delta \mathrm{H}_{\mathrm{m}}(\mathrm{J} / \mathrm{g})$ & crystallinity \\
\hline \multirow[t]{6}{*}{ (O) } & 36 & 57.4 & $76 \%$ & 76 & $48 \%$ \\
\hline & 57 & 61.3 & $84 \%$ & 102 & $59 \%$ \\
\hline & 67 & 56.5 & $86 \%$ & 101 & $57 \%$ \\
\hline & 95 & 63.8 & $89 \%$ & 108 & $59 \%$ \\
\hline & 138 & 63.3 & $92 \%$ & 141 & $74 \%$ \\
\hline & 139 & 64.7 & $93 \%$ & 137 & $72 \%$ \\
\hline \multirow[t]{3}{*}{ (NO) } & 39 & 61.1 & $75 \%$ & 97 & $61 \%$ \\
\hline & 57 & 61.7 & $82 \%$ & 116 & $69 \%$ \\
\hline & 112 & 62.5 & $90 \%$ & 137 & $73 \%$ \\
\hline \multirow[t]{3}{*}{$(\mathrm{ON})$} & 39 & 60.0 & $75 \%$ & 80 & $51 \%$ \\
\hline & 48 & 60.3 & $79 \%$ & 85 & $52 \%$ \\
\hline & 129 & 64.1 & $91 \%$ & 138 & $74 \%$ \\
\hline (NOO) & 20 & N.D. & $59.5 \%$ & N.D. & N.D. \\
\hline
\end{tabular}




\begin{tabular}{|l|l|l|l|l|l|}
\hline & 44 & 62.1 & $76 \%$ & 98 & $62 \%$ \\
\hline & 65 & N.D. & $83 \%$ & N.D. & N.D. \\
\hline & 81 & 61.9 & $86 \%$ & 119 & $67 \%$ \\
\hline & 108 & 62.1 & $89 \%$ & 121 & $66 \%$ \\
\hline & 117 & 63.1 & $90 \%$ & 121 & $66 \%$ \\
\hline & 170 & N.D. & $93 \%$ & N.D. & N.D. \\
\hline & & & & & \\
\hline & 27 & 60.1 & $67 \%$ & 75 & $54 \%$ \\
\hline & 43 & 61.6 & $77 \%$ & 100 & $63 \%$ \\
\hline & 115 & 62.5 & $90 \%$ & 132 & $71 \%$ \\
\hline & & & & & \\
\hline & 30 & 56.8 & $72 \%$ & 68 & $46 \%$ \\
\hline & 55 & 62.6 & $83 \%$ & 105.7 & $62 \%$ \\
\hline (Sox) $\boldsymbol{C}^{\prime}$ & 40 & & & & \\
\hline & 74 & N.D. & $76 \%$ & N.D. & N.D. \\
\hline & & N.D. & $85 \%$ & N.D. & N.D. \\
\hline PHS & 15 & 59.9 & $67 \%$ & 40 & $29 \%$ \\
\hline & 47 & 62.2 & $87 \%$ & 94 & $53 \%$ \\
\hline & 78 & 63.9 & $91 \%$ & 129 & $68 \%$ \\
\hline
\end{tabular}

From the data, it can be observed that, in the series of $(\mathbf{O}),(\mathbf{O N})$, and (OOO) (for example, the group shaded in yellow), the polyanions with fewer substituents generally exhibit stronger suppression of PEO crystallization. This trend matches that observed for the conductivities, and is similar to what was observed on small molecule salts in the literature. ${ }^{10} \mathrm{We}$ suggest that in this series, the lithium/PEO interaction dominates the material properties, which was is directly related to salt dissociation.

However, comparing (NO) and (NOO) (red and green groups), it is found that the suppression of crystallinity is not correlated with ionic conductivities. This observation indicates that the polyanion chains can also have important interaction with PEO chains, which will eventually affect the crystallinity and conductivity.

Also, it is noted that comparing with our materials, PHS samples seem to have even stronger suppression effects over PEO crystallization, which do not result in higher conductivity values.

$\mathrm{X}$-ray scattering was conducted at Argonne Nation Lab beamline 12-ID-B. The following representative profile was obtained at $80^{\circ} \mathrm{C}$. The peak at $\sim 4 \AA^{-1}$ was assigned to the Kapton tape. From these traces, the absence of ordered nanostructure can be confirmed. The slopes of the low q region were calculated to be 3.2 , indicating relative homogeneous mixing of the polyanions and PEO. 


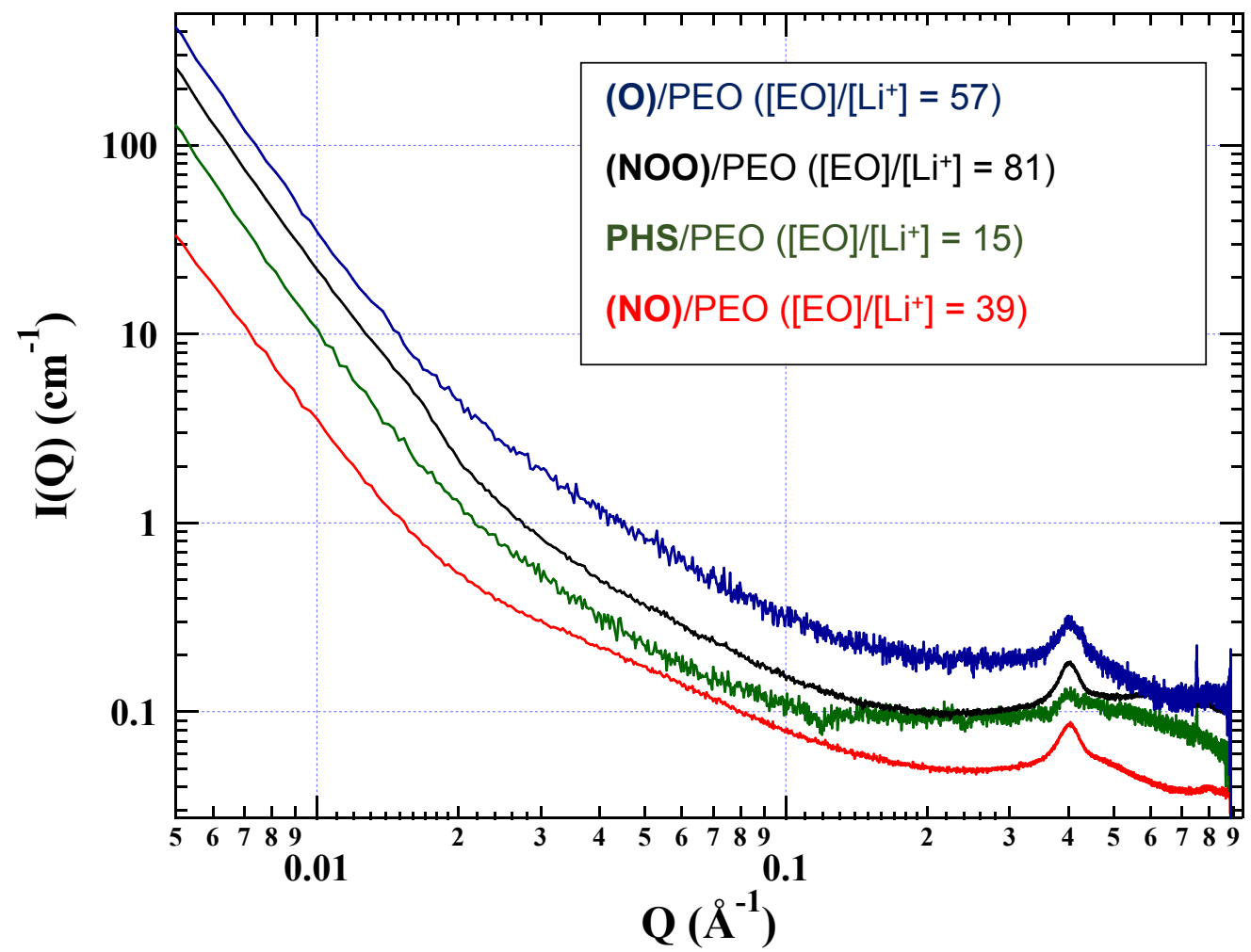

Figure S47. Small-angle X-ray scattering profiles of representative samples. 


\section{S8. Ion diffusion in PEO}

Pulsed field gradient nuclear magnetic resonance (PFG-NMR) measurements to determine self-diffusion coefficients of ${ }^{7} \mathrm{Li}$ and ${ }^{19} \mathrm{~F}$ were performed on a ECX400 spectrometer (JEOL) equipped with a $9.4 \mathrm{~T}$ (400 $\mathrm{MHz}$ ) narrow bore superconducting magnet and a pulse gradient probe (maximum gradient $\sim 13 \mathrm{~T} / \mathrm{m}, \mathrm{JEOL}$ ), using a bipolar pulse-pair longitudinal eddy current delay (BPP-LED) pulse sequence with sinusoidal PFG at $80{ }^{\circ} \mathrm{C}$. The experimental procedure for PFG-NMR was described in previous report. ${ }^{11}$

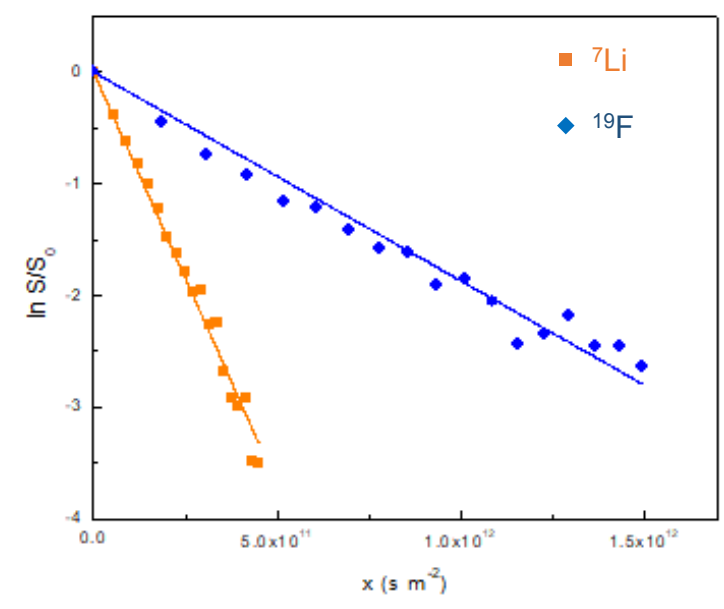

\begin{tabular}{|l|l|l|l|}
\hline & $\boldsymbol{D}_{\text {ave }}\left(\mathbf{1 0}^{-\mathbf{8}} \mathbf{c m}^{\mathbf{2}} \mathbf{s}\right)$ & $\begin{array}{l}\text { Standard deviation } \\
\left(\mathbf{1 0}^{-\mathbf{8}} \mathbf{c m}^{\mathbf{2}} \mathbf{s}\right)\end{array}$ & $\begin{array}{l}\text { Standard Error } \\
\left(\mathbf{1 0}^{-\mathbf{8}} \mathbf{c m}^{\mathbf{2}} / \mathbf{s}\right)\end{array}$ \\
\hline${ }^{7} \mathrm{Li}$ & 7.1 & 0.88 & 0.28 \\
\hline${ }^{19} \mathrm{~F}$ & 1.7 & 0.24 & 0.098 \\
\hline
\end{tabular}

Figure S48. PFG-NMR results for (NO)/PEO $([\mathrm{EO}] /[\mathrm{Li}+]=36)$. 


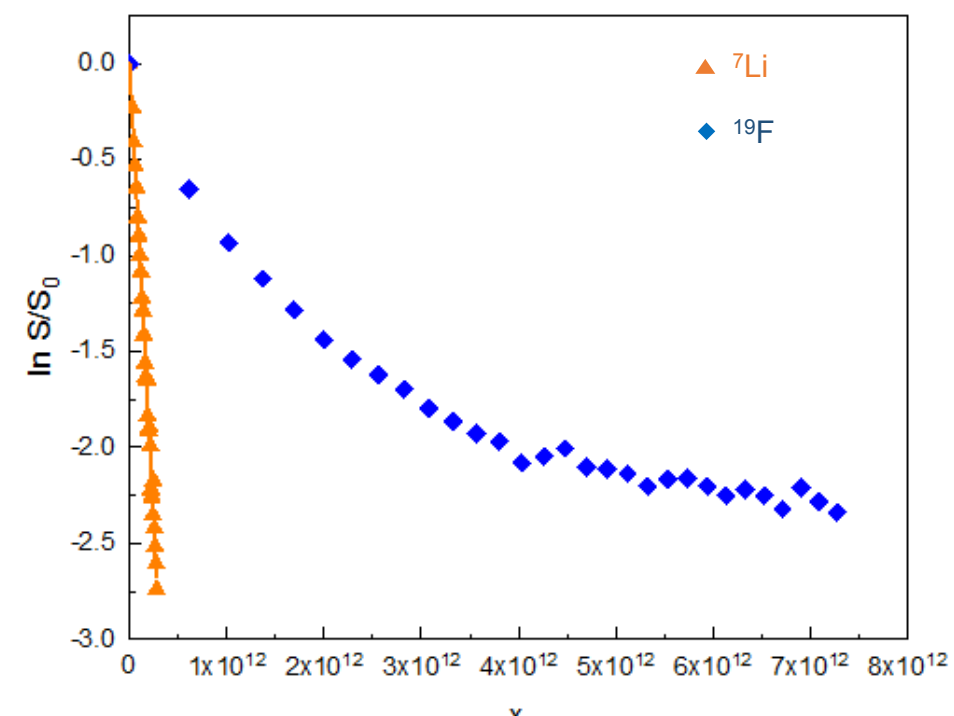

Figure S49. PFG-NMR results of $(\mathbf{O})$ in PEO $\left([\mathrm{EO}] /\left[\mathrm{Li}^{+}\right]=36\right)$. The ${ }^{19} \mathrm{~F}$ signal was fitted with a biexponential function, $\mathrm{y}=\ln \left(\mathrm{P}_{1} \exp \left(-\mathrm{xP}_{2}\right)+\left(1-\mathrm{P}_{1}\right) \exp \left(-\mathrm{xP}_{3}\right)\right)$, where $\mathrm{x}=4 \gamma^{2} \delta^{2} \mathrm{~g}^{2} \pi^{-2}(\Delta-5 \delta / 16-\tau / 2)$. Fitting the plot provided $\mathrm{P}_{2}=\mathrm{D}_{\mathrm{F}, 1}$ and $\mathrm{P}_{3}=\mathrm{D}_{\mathrm{F}, 2}$ with $\mathrm{P}_{1}$ being the population percentage of $\mathrm{D}_{\mathrm{F}, 1}$ species. It was found that $\mathrm{D}_{\mathrm{F}, 1}=1.2 * 10^{-8} \mathrm{~cm}^{2} / \mathrm{s}, \mathrm{D}_{\mathrm{F}, 2}=0.1(1) * 10^{-8} \mathrm{~cm}^{2} / \mathrm{s}$, and $\mathrm{P}_{1}=0.8$. Lithium diffusion was found to be $\mathrm{D}_{\mathrm{Li}}=9.5 * 10^{-8} \mathrm{~cm}^{2} / \mathrm{s}$.

The equation, $t_{\mathrm{Li}}=\mathrm{D}_{\mathrm{Li}} /\left(\mathrm{D}_{\mathrm{Li}}+\mathrm{D}_{\mathrm{F}}\right)(\mathrm{eq}-1)$, has been often used for the calculation of ion transference numbers; ${ }^{12}$ however, it has been argued that $t_{\mathrm{Li}}=\mathrm{D}_{\mathrm{Li}} /\left(\mathrm{D}_{\mathrm{Li}}+\mathrm{N} * \alpha * \mathrm{D}_{\mathrm{F}}\right)(\mathrm{eq}-2, \mathrm{~N}$ is the number of ionic sites along a polyion chain, and $\alpha$ is the dissociation degree) should give a better estimation of transference number, since anions on the same chain should have correlated movement. ${ }^{13}$ It may be a more accurate estimation to use eq-2 for systems involving a dilute solution of rigid anions with well-defined $\mathrm{N}$ and complete dissociation. In contrast, for polyions, it is difficult to obtain accurate values of $\mathrm{N}$ and $\alpha$, which hinders the practical use of eq-2. Besides, polyions usually have a distribution of molecular weights, which impact the diffusion constant of an individual chain. For flexible polyion chains in high viscosity, the change in chain conformation during diffusion can decrease the extent of correlated motion as well as affecting the dissociation degree, which further complicates the estimation. ${ }^{14,15}$ Thus, in this work, eq- 1 is used to provide a relative value for the understanding of ion transport through these novel materials. 


\section{S9. Polymeric solvate ionic liquids}

To prepare an equimolar mixture of G4 and the repeat unit of (S)', the vacuum-dried polymer (in Li form) and G4 (dried over molecular sieves) were dissolved in a small amount of tetrahydrofuran (THF; dried over molecular sieves) in an Argon glove box $\left(\mathrm{H}_{2} \mathrm{O}<0.1 \mathrm{ppm}, \mathrm{O}_{2}<0.1 \mathrm{ppm}, \mathrm{MBraun}, \mathrm{USA}\right)$; the mixture was stirred until a homogeneous solution was obtained. The mixture was then dried under vacuum for $24 \mathrm{~h}$ to remove THF without exposure to the atmosphere. The equimolar mixture of G4 and LiTFSI, LiTFSI/G4, was prepared by directly mixing G4 and LiTFSI without a cosolvent in the same Ar glove box.

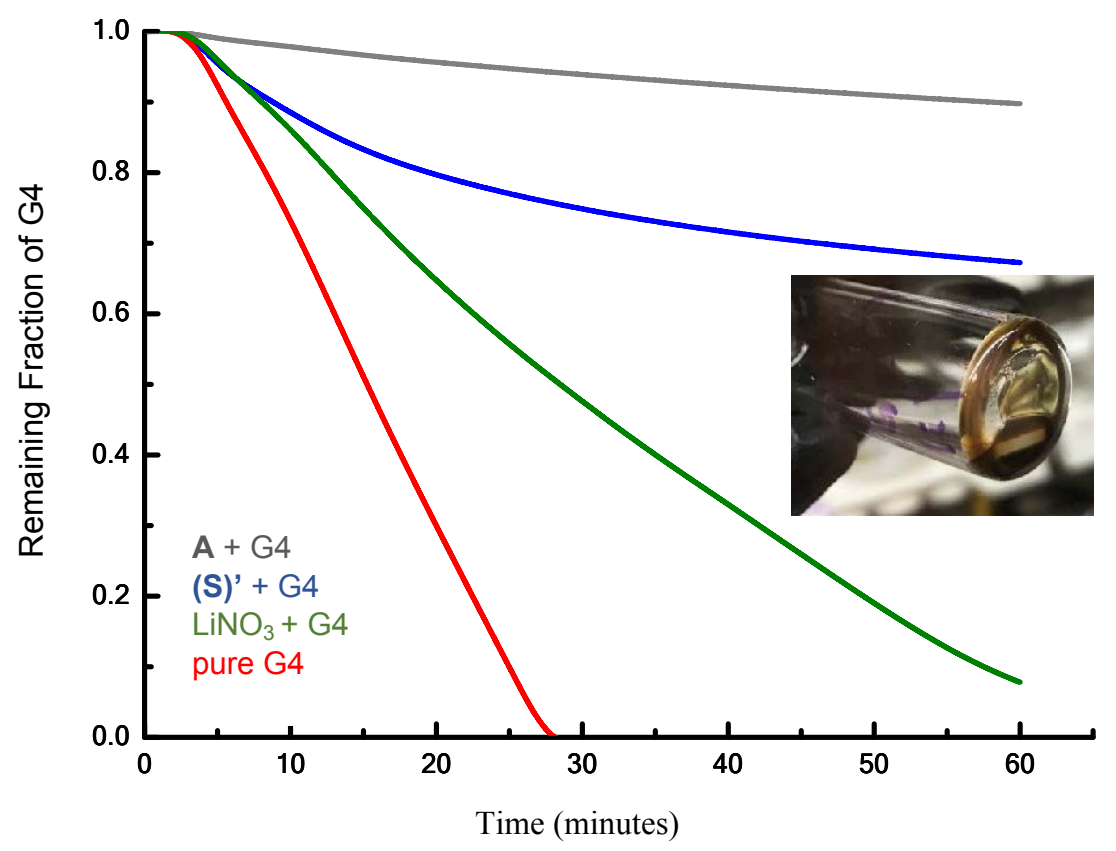

Figure S50. Thermogravimetric analysis of salt $+\mathrm{G} 4$ complexes were conducted with a TA Q50 instrument at $120{ }^{\circ} \mathrm{C}$ under $\mathrm{N}_{2}$. The initial delay of mass loss was a result of temperature equilibration. It was found that pure $\mathrm{G} 4$ was quickly ( $<30$ minutes) evaporated, while $\mathrm{LiNO}_{3}+\mathrm{G} 4$ showed a decelerated evaporation (90\% weight loss within $60 \mathrm{~min}$ ). A + G4 (in Li form) showed excellent thermal stability with a weight loss rate $\sim 0.0014 / \mathrm{min}$ ("ideal" solvated ionic liquid LiTFSI + G4 is $\sim 0.0005 / \mathrm{min}$, not shown here), indicating the formation of strong coordination between $\mathrm{Li}^{+}$and G4. For (S)' $+\mathrm{G} 4$, an initial quick loss of mass was observed and assigned to excess G4. After the early stage, the material exhibited a slow loss of G4, where the rate is $\sim 0.0024 / \mathrm{min}$ (comparing with $\sim 0.014 / \mathrm{min}$ for $\mathbf{A}+\mathrm{G} 4$ ). This result shows that the (S)' $+\mathrm{G} 4$ forms a strong complex, comparable with $\mathbf{A}+\mathrm{G} 4$. The digital image shows apparent homogeneity and fluidity of (S)' + G4 with a white stir bar as reference. 


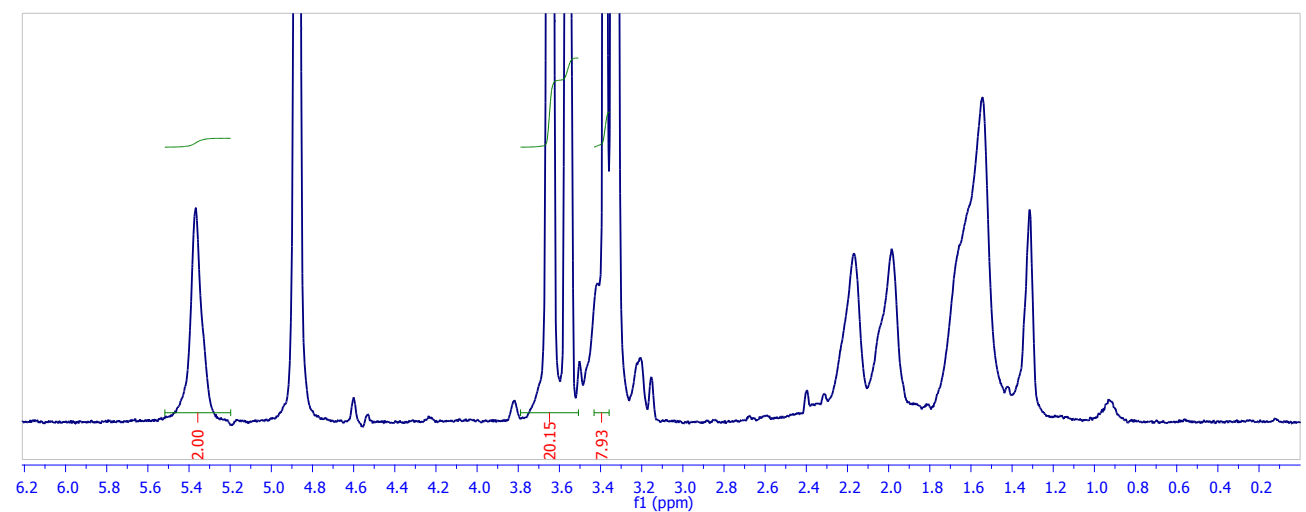

Figure S51. ${ }^{1} \mathrm{H}$ NMR spectrum of (S)' $+\mathrm{G} 4$ in $\mathrm{d}_{4}$-methanol, showing that there are $\sim 1.25-1.32$ equivalents of $\mathrm{G} 4$ relative to $\mathrm{Li}^{+}$.

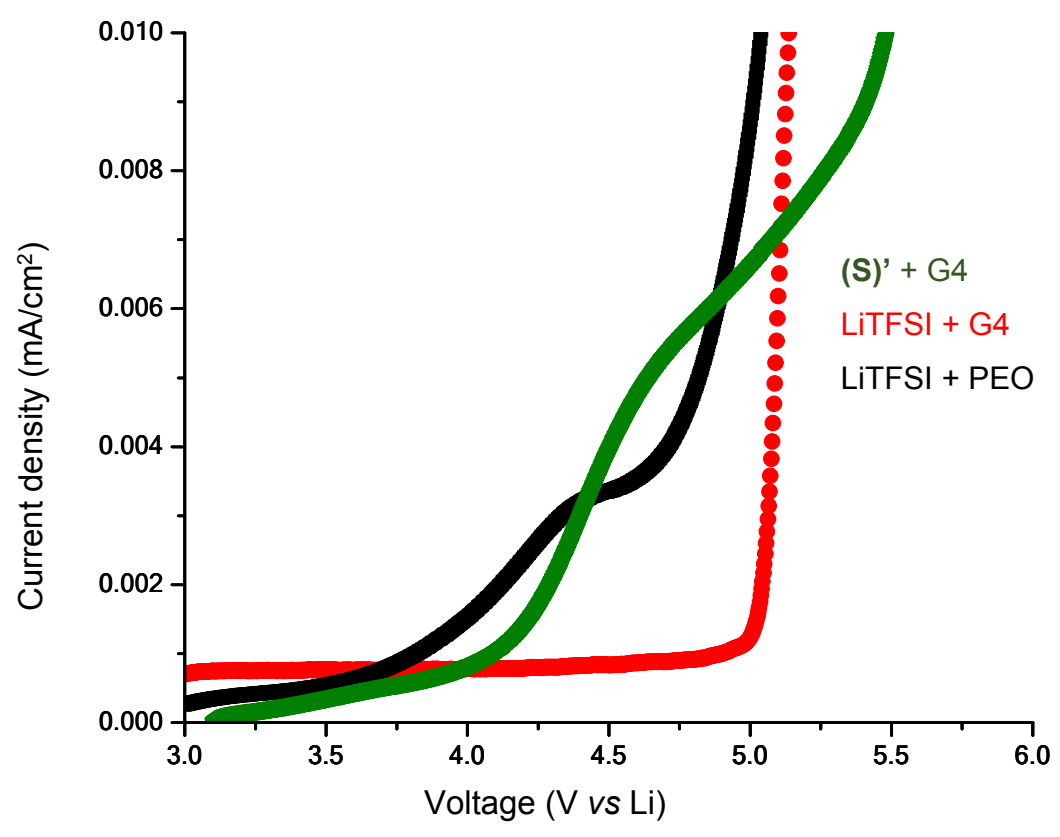

Figure S52. EC stability test. The oxidative stability of (S)' + G4 and LiTFSI + G4 were investigated using linear sweep voltammetry at a scan rate of $1 \mathrm{mV} \mathrm{s}^{-1}$ at $80^{\circ} \mathrm{C}$. Lithium metal foil (Chemetall, Germany) was used as the reference and counter electrode, and a stainless-steel plate (MTI Corp) was used as the working electrode. All electrochemical tests were conducted employing a VMP3 potentiostat (BioLogic Science Instruments). It is observed that (S)' + G4 exhibited a later onset of oxidation than LiTFSI + PEO. The current is assigned to the small excess of G4 molecules. 


\section{S10. Discussion on ion dissociation}

According to the Manning counterion condensation theory of rigid polyelectrolytes (mean-field PoissonBoltzmann equation), ${ }^{16,17}$ the degree of ion dissociation can be estimated by

$$
\alpha \sim l / l_{\mathrm{B}}=l /\left(e^{2} / \varepsilon k \mathrm{~T}\right)
$$

where $l$ is the average distance between adjacent sulfonimide groups, $l_{\mathrm{B}}$ is the Bjerrum length, $e$ is the electron charge, $k \mathrm{~T}$ stands for the thermal energy, while $\varepsilon$ denotes the dielectric constant and should be similar for these materials. Assuming a rigid backbone conformation, the cyclooctene backbone is expected to provide $\sim 3$ times higher degree of ion dissociation compared to a model polystyrene backbone. However, this may be a better description at higher $[\mathrm{EO}] /[\mathrm{Li}]$ ratios and is considered as an overestimation by neglecting the non-uniform charge distribution and chain flexibility. ${ }^{18}$ 


\section{References}

(1) Clark, P. G.; Guidry, E. N.; Chan, W. Y.; Steinmetz, W. E.; Grubbs, R. H. Synthesis of a Molecular Charm Bracelet via Click Cyclization and Olefin Metathesis Clipping. J. Am. Chem. Soc. 2010, 132 (10), 3405-3412.

(2) Meziane, R.; Bonnet, J.-P.; Courty, M.; Djellab, K.; Armand, M. Single-Ion Polymer Electrolytes Based on a Delocalized Polyanion for Lithium Batteries. Electrochim. Acta 2011, 57 (1), 14-19.

(3) Frisch, M. J.; Trucks, G. W.; Schlegel, H. B.; Scuseria, G. E.; Robb, M. A.; Cheeseman, J. R.; Scalmani, G.; Barone, V.; Mennucci, B.; Petersson, G. A.; Nakatsuji, H.; Caricato, M.; Li, X.; Hratchian, H. P.; Izmaylov, A. F.; Bloino, J.; Zheng, G.; Sonnenberg, J. L.; Hada, M.; Ehara, M.; Toyota, K.; Fukuda, R.; Hasegawa, J.; Ishida, M.; Nakajima, T.; Honda, Y.; Kitao, O.; Nakai, H.; Vreven, T.; Montgomery Jr., J. A.; Peralta, J. E.; Ogliaro, F.; Bearpark, M.; Heyd, J. J.; Brothers, E.; Kudin, K. N.; Staroverov, V. N.; Kobayashi, R.; Normand, J.; Raghavachari, K.; Rendell, A.; Burant, J. C.; Iyengar, S. S.; Tomasi, J.; Cossi, M.; Rega, N.; Millam, J. M.; Klene, M.; Knox, J. E.; Cross, J. B.; Bakken, V.; Adamo, C.; Jaramillo, J.; Gomperts, R.; Stratmann, R. E.; Yazyev, O.; Austin, A. J.; Cammi, R.; Pomelli, C.; Ochterski, J. W.; Martin, R. L.; Morokuma, K.; Zakrzewski, V. G.; Voth, G. A.; Salvador, P.; Dannenberg, J. J.; Dapprich, S.; Daniels, A. D.; Farkas, O.; Foresman, J. B.; Ortiz, J. V; Cioslowski, J.; Fox, D. J. Gaussian09 Revision D.01, Gaussian Inc. Wallingford CT; 2010.

(4) Becke, A. D. Density-Functional Thermochemistry. III. The Role of Exact Exchange. J. Chem. Phys. 1993, 98 (7), 5648-5652.

(5) Lee, C.; Yang, W.; Parr, R. G. Development of the Colle-Salvetti Correlation-Energy Formula into a Functional of the Electron Density. Phys. Rev. B 1988, 37 (2), 785-789.

(6) Cossi, M.; Rega, N.; Scalmani, G.; Barone, V. Energies, Structures, and Electronic Properties of Molecules in Solution with the C-PCM Solvation Model. J. Comput. Chem. 2003, 24 (6), 669681.

(7) Barone, V.; Cossi, M. Quantum Calculation of Molecular Energies and Energy Gradients in Solution by a Conductor Solvent Model. J. Phys. Chem. A 1998, 102 (11), 1995-2001.

(8) Ziegler, M. J.; Madura, J. D. Solvation of Metal Cations in Non-Aqueous Liquids. J. Solution Chem. 2011, 40 (8), 1383-1398.

(9) Thelen, J. L.; Chen, X. C.; Inceoglu, S.; Balsara, N. P. Influence of Miscibility on Poly(Ethylene Oxide) Crystallization from Disordered Melts of Block Copolymers with Lithium and Magnesium Counterions. Macromolecules 2017, 50 (12), 4827-4839.

(10) Karmakar, A.; Ghosh, A. A Comparison of Ion Transport in Different Polyethylene OxideLithium Salt Composite Electrolytes. J. Appl. Phys. 2010, 107 (10), 104113.

(11) Ugata, Y.; Thomas, M. L.; Mandai, T.; Ueno, K.; Dokko, K.; Watanabe, M. Li-Ion Hopping Conduction in Highly Concentrated Lithium Bis(Fluorosulfonyl)Amide/Dinitrile Liquid Electrolytes. Phys. Chem. Chem. Phys. 2019, 21 (19), 9759-9768.

(12) Buss, H. G.; Chan, S. Y.; Lynd, N. A.; McCloskey, B. D. Nonaqueous Polyelectrolyte Solutions as Liquid Electrolytes with High Lithium Ion Transference Number and Conductivity. ACS Energy Lett. 2017, 2 (2), 481-487.

(13) Fong, K. D.; Self, J.; Diederichsen, K. M.; Wood, B. M.; McCloskey, B. D.; Persson, K. A. Ion Transport and the True Transference Number in Nonaqueous Polyelectrolyte Solutions for 
Lithium Ion Batteries. ACS Cent. Sci. 2019, 5 (7), 1250-1260.

(14) Borukhov, I. Charge Renormalization of Cylinders and Spheres: Ion Size Effects. J. Polym. Sci. Part B Polym. Phys. 2004, 42 (19), 3598-3615.

(15) Manning, G. S. Counterion Condensation on Charged Spheres, Cylinders, and Planes $\dagger$. J. Phys. Chem. B 2007, 111 (29), 8554-8559.

(16) Manning, G. S. Limiting Laws and Counterion Condensation in Polyelectrolyte Solutions I. Colligative Properties. J. Chem. Phys. 1969, 51 (3), 924-933.

(17) Kuhn, P. S.; Levin, Y.; Barbosa, M. C. Rodlike Polyelectrolytes in the Presence of Monovalent Salt. Macromolecules 1998, 31 (23), 8347-8355.

(18) Schiessel, H. Counterion Condensation on Flexible Polyelectrolytes: Dependence on Ionic Strength and Chain Concentration. Macromolecules 1999, 32 (17), 5673-5680. 